Mederos Martín, A. (2018): “Emilio Camps Cazorla, profesor ayudante de GómezMoreno y director electo del Museo Arqueológico Nacional (1903-1952)", Spal 27.2: 287-314. DOI: http://dx.doi.org/10.12795/spal.2018i27.24

\title{
EMILIO CAMPS CAZORLA, PROFESOR AYUDANTE DE GÓMEZ-MORENO Y DIRECTOR ELECTO DEL MUSEO ARQUEOLÓGICO NACIONAL (1903-1952)
}

\author{
EMILIO CAMPS CAZORLA, ASSISTANT PROFESSOR OF GÓMEZ-MORENO AND \\ ELECTED DIRECTOR OF THE NATIONAL ARCHAEOLOGICAL MUSEUM (1903-1952)
}

\author{
ALFREDO MEDEROS MARTÍN \\ Departamento de Prehistoria y Arqueología de la Universidad Autónoma de Madrid. \\ Facultad de Filosofía y Letras. Campus de Cantoblanco. 28.049 Madrid. \\ Correo-e: alfredo.mederos@uam.es. ORCID: https://orcid.org/0000-0002-0036-7940
}

\begin{abstract}
Resumen: Emilio Camps Cazorla comenzó a colaborar con Gómez-Moreno en el Centro de Estudios Históricos desde 1916, y se licenció en 1925. Se especializó en arquitectura visigoda, asturiana, califal, mozárabe y mudéjar, los temas que mejor dominaba Gómez-Moreno. A partir del curso académico 1929-30, con 26 años, se convirtió en el Profesor Ayudante de la cátedra de doctorado de Arqueología Arábiga en la Universidad de Madrid y en 1930 entró como conservador en el Museo Arqueológico Nacional. Opositó dos veces para suceder a Gómez-Moreno en su cátedra al jubilarse en 1935, primero en junio de 1936, oposición que no se pudo celebrar, y de nuevo en 1941. En ambas oposiciones tuvo como principal contendiente a José Camón Aznar, que desempeñaba, como docencia acumulada, la cátedra de la Arqueología, Epigrafía y Numismática en Salamanca desde 1928. Camón ganó la cátedra en 1941, favorecido por el cambio en el Ministerio de Educación Nacional del perfil de la plaza, de Arqueología Medieval a Arte Medieval. Camps optó también dos veces a la dirección del Museo Arqueológico Nacional en 1940 y 1951. La dirección fue concedida para Taracena en 1940. Lo volvió a intentar al dimitir Navascués como director interino en 1951, siendo nombrado director por Orden Ministerial de 15 de enero, pero su muerte inesperada, el 28 de enero de 1952, con sólo 48 años, impidió que tomara posesión. Sus principales excavaciones fueron el poblado del Bronce Final y Hierro de Sanchorreja (Ávila) entre 1931-35, la necrópolis visigoda de Castiltierra (Segovia) entre 1932-34/35 y la ciudad califal omeya de Medina Azahara (Córdoba) entre 1943-47.
\end{abstract}

\begin{abstract}
Emilio Camps Cazorla began to collaborate with Gómez-Moreno in the Center of Historical Studies from 1916, and graduated in 1925. He specialized in Visigoth, Asturian, Caliph, Mozarabic and Mudéjar architecture, the main subjects that Gomez-Moreno. From the academic year 1929-30, at the age of 26, he became the Assistant Professor of the $\mathrm{PhD}$ degree in Islamic Archeology at the University of Madrid and in 1930 entered as a curator at the National Archaeological Museum. He opposed twice to succeed Gómez-Moreno in his chair when he retired in 1935, first in June 1936, an opposition that could not be celebrated, and again in 1941. In both oppositions Jose Camón Aznar was the main contender, who has, as accumulated teaching, the professorship of Archeology, Epigraphy and Numismatics in Salamanca since 1928. Camón won the chair in 1941, favored by the change in the Ministry of National Education in the profile of the Professorship, from Medieval Archeology to Medieval Art. Camps also twice opted for the direction of the National Archaeological Museum in 1940 and 1951. First was granted to Taracena in 1940 . He returned to try when Navascués resign as interim director in 1951, being appointed director by Ministerial Order of January 15, but his unexpected death, on January 28,1952 , only with 48 years old, prevented him from taking possession. His main archaeological field research was the settlement of the Late Bronze Age and Iron Age of Sanchorreja (Avila) between 1931-35, the Visigoth necropolis of Castiltierra (Segovia) between 1932-34 and the Umayyad caliph city of Madīnat al-Zahrā' (Córdoba) between 1943-47.
\end{abstract}


Palabras clave: Emilio Camps; Museo Arqueológico Nacional; Cátedra de Arqueología Arábiga; Camón Aznar.

\section{INTRODUCCIÓN}

La trayectoria científica de Emilio Camps viene marcada por dos hechos negativos que impidieron que fuera el primer catedrático de Arqueología Medieval de la Universidad de Madrid y el Director del Museo Arqueológico Nacional. Profesor Ayudante de GómezMoreno en Arqueología Árabe en la Universidad de Madrid, desde 1929, el estallido de la Guerra Civil imposibilitó que accediera a la nueva cátedra de Arqueología Medieval al interrumpirse el concurso que se iba a celebrar a partir del 25 de junio de 1936. Al cambiar el Ministerio de Educación el perfil de la plaza de Arqueología Medieval a Historia del Arte Medieval en 1941, facilitó que la ganase el ya catedrático y miembro de Falange desde enero de 1937, José Camón Aznar. Por otra parte, ya propuesto por el Patronato del Museo Arqueológico Nacional como sustituto de Taracena, tras su fallecimiento en 1951, sufrió también una muerte inesperada el 28 de enero de 1952, con sólo 48 años, que impidió que tomara posesión del cargo para que el que había sido elegido según Orden Ministerial del 15 de enero. No obstante, su trayectoria académica e investigadora merece un análisis en profundidad que nunca se ha afrontado hasta el momento, pues sus mejores datos biográficos personales, con apenas 3 páginas, son las breves notas póstumas que redactó Gómez-Moreno (1953: 7-9) en la introducción de un libro de Camps, que en parte se basan en el curriculum que presentó a la dirección del Museo Arqueológico Nacional (AGA [Archivo General de la Administración] 31/4643).

\section{ENTORNO FAMILIAR}

Emilio Camps Cazorla, al que pusieron los nombres de Emilio José Urbano Antonio de la Santísima Trinidad, nació el 31 de octubre de 1903 en Fuentesanta de Martos (Jaén), en el suroeste de la provincia, donde su padre era maestro. Sus padres procedían de Granada y entonces residían en la calle Santuario. Emilio Camps y Cortés tenía 35 años, mientras que su mujer Carmen Cazorla Quirosa contaba con 30 años al nacer Emilio. Un hermano de su madre, José Cazorla Quirosa, era funcionario del Cuerpo Facultativo de Archiveros, Bibliotecarios y Arqueólogos desde 1915. Su abuelo
Keywords: Emilio Camps; National Archaeological Museum; Professorship of Islamic Archeology; Camón Aznar.

paterno procedía de Granada, Emilio Camps de Cantos, mientras que la abuela era originaria de Valencia, Emilia Cortés Gaya, residiendo en Jaén en casa de su hijo. Los abuelos maternos ya habían muerto, y ambos eran originarios de Granada, Francisco Cazorla Vidal y Angustias Quirosa Lapido (AGA 32/14055/20; AGA 31/4643/14; AGUCM [Archivo General de la Universidad Complutense de Madrid] TIT-212).

Al morir el padre, su madre Carmen Cazorla regresó a Granada a la vivienda de su familia, con Emilio y su hermana María, unos 4 años más pequeña que Emilio. Muy pronto los tres se trasladaron a Madrid a la vivienda de un tío materno en la calle Fuencarral, Francisco Cazorla Quirosa, músico en la banda municipal de Madrid, aficionado también a la epigrafía latina (Gómez-Moreno Martínez 1953: 8; T. Camps com. pers.), "tito Paco" (Camps 1930/2015: 64 n. 3, 294). Francisco Cazorla estaba casado con María Luisa Martín, y tenía tres hijos, que fueron como hermanos pequeños de Emilio: Paco, que tuvo una Academia para la preparación de aparejadores y delineantes; María Luisa, que trabajó en el Ministerio de Hacienda (T. Camps com. pers.). La tercera, Angustias Cazorla, fue encargada de la reorganización de la biblioteca del Museo Arqueológico Nacional cobrando 175 pesetas mensuales al menos desde septiembre de 1939 (AMAN [Archivo del Museo Arqueológico Nacional] Libro Actas Patronato $\mathrm{n}^{\mathrm{o}} 84$, p. 5v) y más tarde llegó a ser la secretaria de los directores como Navascués o Almagro Basch. Su hermana, María Camps, trabajó en un departamento de la compañía Telefónica (T. Camps com. pers.).

Desde al menos 1929, hasta el inicio de la Guerra Civil, Emilio residió en la calle Andrés Mellado 32 $2^{\circ}$ izq., en el barrio de Argüelles, junto a su madre y hermana. En "casa (...) me encuentro con que mamá y María se han ido [a] casa de don Manuel" (Camps 1930/2015: 338, 79 n. 3, 109 n. 64), indicativo que toda la familia tenía amistad con la familia de Gómez-Moreno. Esta vivienda la abandonaron por los combates en diciembre de 1936, pasando a vivir en la calle Apodaca $4^{\circ}$ piso izq. hasta el final de la guerra (AMAN EP ECC 32-33; AGA 31/6054/34; AGA 31/4643).

Después de la Guerra Civil se casó con la maestra nacional Petra Blanco Rivas, dos años menor que Emilio, que había sido profesora en Betanzos (La Coruña) y después lo fue en el grupo escolar de Chamberí en 
Madrid. Se habían conocido hacia 1934, pero por seguridad no tuvieron contacto durante la guerra, casándose en 1941 en la iglesia de San Francisco el Grande (T. Camps com. pers.; Laínez 1953: 95). Era la menor de cuatro hermanos, dos chicos, Florentino y Saturio Blanco Rivas, y una chica, Balbina. Fueron a vivir en la calle Bretón de los Herreros 60, $5^{\circ}$ izq., y el 18 de mayo de 1944 nació su única hija, María Teresa Camps Blanco, que sólo tenía 7 años cuando falleció su padre en 1952 con 48 años (AMAN EP ECC 78; AGA 31/4643; T. Camps com. pers.). Su mujer Petra siguió trabajando como maestra hasta su jubilación y falleció el 5 de julio de 1970 ( $A B C$ 9-7-1970: 103; T. Camps com. pers.).

\section{ESTUDIOS DE BACHILLERATO}

Cuando comenzó sus estudios de Bachillerato ya residía en Madrid, pues realizó el examen de ingreso en el Instituto San Isidro el 21 de junio de 1916 (AGUCM TIT-212), cursando el primer año de Bachillerato de 1915-16 en las Escuelas Pías de San Antón (GómezMoreno Martínez 1953: 8), con las asignaturas Nociones y Ejercicios de Aritmética, Caligrafia y Religión (1), Lengua Castellana y Geografía General de Europa. A partir de su segundo año, dependiendo del Instituto General y Técnico del Cardenal Cisneros, junto a la Universidad Central de Madrid, en la calle de San Bernardo, mejoró notablemente sus calificaciones. En el curso 1916-17 tuvo Lengua Latina (1), Geografía General de España, Aritmética y Religión (2), Gimnasia (1), matriculándose también en Gimnasia (2) del curso siguiente (AGUCM TIT-212).

De la capacidad de Camps quizás el mejor ejemplo fue el curso 1917-18, cuando realizó $3^{\circ}$ y $4^{\circ}$ de Bachillerato en el mismo año. En el tercer curso tuvo Lengua Latina (1), Lengua Francesa (1), Historia de España y Geometría. En todas las asignaturas de cuarto curso, Preceptiva Literaria y Composición, Lengua Francesa (2), Historia Universal, Dibujo (1) y Algebra y Trigonometría obtuvo sobresaliente (AGUCM TIT-212).

Sin embargo, hubo algún problema familiar en el curso 1918-19, pues solo se examinó de las asignaturas en convocatoria extraordinaria y bajaron las calificaciones ese $5^{\circ}$ curso, obteniendo en Física y en Dibujo (2) un notable, mientras que en Psicología y Lógica, Elementos de Historia General de la Literatura y en Fisiología e Higiene tuvo la calificación de aprobado. En el último y $6^{\circ}$ curso de 1919-20, mejoró las notas del curso anterior, y obtuvo en Ética y Rudimentos del Derecho un sobresaliente; en Química General y en Historia Natural un notable, mientras que en Agricultura y Técnica Agrícola e Industrial solo tuvo aprobado. Solicitó el título de Bachiller el 14 de mayo de 1922 (AGUCM TIT-212), dos cursos después de finalizarlo, indicativo que no tenía previsto o no se pudo matricular inmediatamente en la universidad

Al iniciar su segundo curso de bachillerato se incorporó como dibujante en la sección de Arqueología del Centro de Estudios Históricos, para preparar documentación gráfica para Gómez-Moreno con apenas 13 años, en 1916 (Gómez-Moreno Martínez 1953: 7), y el propio Camps lo señala también en su relación de méritos para la dirección del Museo Arqueológico Nacional (AGA 31/4643). Recibía el apelativo cariñoso de Campitos por los miembros del Centro de Estudios Históricos, ya que se incorporó muy joven (Carriazo 1972/2001: 175). Su tío, Francisco Cazorla, había sido compañero de Gómez-Moreno en el Bachillerato en Granada y por entonces uno de sus dos mejores amigos (Gómez-Moreno Rodríguez, 1995: 43). .

Se ha planteado que comenzó a trabajar como auxiliar contable de banca a la vez que comenzó los estudios en la universidad (Gil Farrés 1952b: 130; Pasamar y Peiró 2002: 155). No obstante, en una declaración suya en 1939 indica que "trabajó el firmante más de 14 años" en el "Instituto Católico de Artes e Industrias de Madrid" (AGA 31/6054/37). El Instituto fue fundado por la Compañía de Jesús en 1905, en la actual calle Alberto Aguilera 23-25, hasta su incendio el 11 de mayo de 1931, poco después de haberse proclamado la Segunda República. Si hacemos el cálculo nos sitúa en 1917 o 1916, lo que implica que comenzó a trabajar también allí a la vez que en el Centro de Estudios Históricos.

Seguramente resultado de su trabajo allí surgió su relación con Pedro Miguel de Artiñano y Galdácano, catedrático de la Escuela Central de Ingenieros Industriales y crítico de arte, a quien Camps (1930/2015: 79) escribió al llegar a Roma.

\section{ESTUDIOS UNIVERSITARIOS}

Se matriculó en Filosofía y Letras el curso 1922-23, haciendo el año de comunes las asignaturas de Lengua y Literatura Española, con sobresaliente y Matrícula de Honor, Lógica Fundamental con notable y en Historia de España solo un aprobado. No obstante, optó por la especialidad de Historia en el curso 192324 , pero volvió a tener la mejor nota en una asignatura de arte, Teoría de la literatura y de las Artes con 
sobresaliente, en Lengua y Literatura Latinas un notable, mientras en Historia Antigua y Media de España, de nuevo, apenas un aprobado. En la cuarta asignatura, Historia Universal, se matriculó el primer curso de 1922-23, no presentándose inicialmente, obteniendo después un aprobado en la convocatoria extraordinaria y finalmente en septiembre consiguió un sobresaliente y Matrícula de Honor.

Su último curso de 1924-25 siguió marcado por la irregularidad, en Geografía Politica y Descriptiva sacó un notable y en Paleografía solo obtuvo un aprobado. En cambio, en las específicas de Historia y Arqueología las notas fueron mucho mejores. En Historia Antigua y Media de España y en Numismática y Epigrafía tuvo sobresaliente y Matrícula de Honor. No se presentó en cambio a Historia Moderna y Contemporánea de España e Historia Universal Moderna y Contemporánea, en las cuales obtuvo un aprobado en la convocatoria extraordinaria y finalmente en septiembre se volvió a presentar y tuvo en ambas sobresaliente y Matrícula de Honor (AGA 32/14.055/20). De las que se recomendaban para opositar a Archivos y Bibliotecas, en su último curso de 1924-25 también se matriculó en Lengua Latina (1 ${ }^{\text {er }}$ curso de ampliación) donde obtuvo sobresaliente con Matrícula de Honor, y Bibliología con notable. Al año siguiente, en el curso 1925-26, hizo Lengua Latina ( $2^{\circ}$ curso de ampliación) con un notable (AGA 31/4643). No solicitó el título hasta años después, expedido con fecha del 1 de agosto de 1930 (AGA 32/14.055/20).

\section{EL CENTRO DE ESTUDIOS HISTÓRICOS}

El Centro de Estudios Históricos tuvo su primera sede en los bajos de la Biblioteca Nacional, y posteriormente se cambió a un pequeño palacio en la calle Almagro 26. El primer encargo importante para Camps en el Centro fue realizar los dibujos para un estudio del lazo en el arte islámico que elaboraban Gómez-Moreno y el ingeniero Antonio Prieto Vives, sobrino de Antonio Vives, libro que empezó a imprimirse en 1921, pero que no se finalizó (Gómez-Moreno Rodríguez 1995: 286, 522).

A partir de 1927 comenzó a publicar trabajos científicos, principalmente sobre arquitectura: "Puertas mudéjares con inscripción eucarística" (Camps 1927), Arquitectura cristiana primitiva, visigoda y asturiana (Camps 1929a), "El retablo de la Iglesia Parroquial de Santa Cruz, en Cardeñosa (Ávila)" (Camps 1929b) o Arquitectura califal y mozárabe (Camps 1930), dentro de la línea de trabajo de Gómez-Moreno.
Algún contemporáneo presenta una visión poco idílica del Centro: "Por las tardes acudía al Centro de Estudios Históricos. Mi decepción allí fue muy grande. Después del hervor zaragozano los que alli trabajaban me parecieron primarios, encogidos y sin modernidad (...) Ante su pedantería no podía evitar una punta de desprecio" (Camón Aznar 1984: 15). Era el curso 1922-23, cuando Camón Aznar hizo el doctorado (Gómez-Moreno Rodríguez 1995: 315), y solo menciona a su compañero de promoción, el también zaragozano Sánchez Ventura.

Sin embargo, por ese curso había un notable grupo de investigadores, en Arte se encontraban Elías Tormo, Francisco Javier Sánchez Cantón, Diego Angulo Íñiguez y Enrique Lafuente Ferrari, mientras en Arqueología estaban Manuel Gómez-Moreno, Emilio Camps Cazorla desde 1916 (AGA 31/4643), Juan Cabré y Aguiló desde el curso 1917-18, Cayetano de Mergelina desde octubre de 1920 (AGA 32/13.362) y Juan de Mata Carriazo desde 1922 (AGA 32/13.362).

\section{PROFESOR AYUDANTE DE ARQUEOLOGÍA ARÁBIGA}

Desde el curso 1929-30, Camps fue nombrado Profesor Ayudante de la cátedra de doctorado de Arqueología Arábiga, siendo renovado para el curso de 1930-31 el 30 de septiembre de 1930. Ese mismo día solicitó permiso para marchar en Comisión de Estudios al Extranjero por tres meses entre octubre y diciembre de 1930, para viajar a Italia y Francia. Se reincorporó el 7 de enero, impartiendo clases los lunes, martes y sábados a las 16.30 horas en el Centro de Estudios Históricos (AGUCM P-462/68).

A pesar de la ausencia de Camps entre octubre y diciembre de 1930, dentro del periodo que fue Gómez-Moreno el Director General de Bellas Artes, cuya dimisión fue aceptada por el Rey el 25 de febrero de 1931, según Real Decreto del día siguiente (IGM [Instituto Gómez Moreno] 16.285), debió cubrir buena parte de la docencia de Gómez-Moreno al menos entre enero y febrero de 1931. Meses después, el 7 de noviembre de 1931, el Decano de la Facultad de Filosofía y Letras de la Universidad de Madrid, Claudio Sánchez-Albornoz y Menduiña, mandó un escrito general a los profesores de la facultad:

(...) habiendo llegado hasta mi noticia de que algunos catedráticos descargan habitualmente el trabajo de clase en sus Auxiliares o Ayudantes, me veo en 
la dolorosa precisión de recordar a todos que esto no está permitido por la legislación vigente (...) no puede realizarse tal cargo de modo habitual y continuo cierto número de días a la semana (IGM 16.424).

Como una de las circulares fue a nombre de GómezMoreno, al ser uno de los catedráticos, se lo tomó como algo personal, y le contestó a Sánchez-Albornoz, que días después le escribía a Gómez-Moreno:

¿Qué mosca le ha picado a V. para escribirme una carta suprimiendo el título de amigo? (...) ¿Qué le he hecho para que me apee ahora del tratamiento? (IGM 16.423).

La Ayudantía de Camps fue renovada para el curso 1931-32 el 1 de octubre de 1931, para el curso 1932-33 el 24 de noviembre de 1932, y para el curso 1933-34 el 16 de octubre de 1933. En los dos cursos siguientes se le denomina Ayudante de Clases Prácticas, en 1934 35 renovado el 1 de octubre de 1934 y para el curso 1935-36, nombrado el 8 de octubre de 1935 (AGUCM P-462/68).

En septiembre de 1931, Camps hizo un viaje a Galicia con los alumnos de la asignatura de Doctorado, dirigidos por Tormo y Gómez-Moreno, en el que participaron Enrique Lafuente Ferrari, el ayudante de Tormo y Teresa de Andrés, profesora en el Instituto Escuela, que hacía la tesis doctoral con Gómez-Moreno sobre "Rejería española". La ruta fue Palencia, Valladolid, Galicia, con visita a Santa Tecla, el yacimiento excavado por Mergelina, norte de Portugal, Astorga y Zamora (Gómez-Moreno Rodríguez 1995: 399-400).

Durante este periodo, acompañó a Gómez-Moreno y a los estudiantes de Arqueología Arábiga en marzo de 1932 en una excursión de la facultad de Filosofía y Letras "a las zonas españolas y francesa del protectorado de Marruecos", permiso que solicitó al director del MAN el 7 de marzo y que se le concedió el día 9 para que "se especialice en los estudios de Arqueología Arábiga" (AMAN EP ECC 20-21). En el viaje en autobús, además de los alumnos, participaron Joaquín $\mathrm{M}^{\mathrm{a}}$ Navascués, José Ferrandis y Luis Pérez Bueno, director del Museo de Artes Decorativas, encabezados por Tormo y Gómez-Moreno (Gómez-Moreno Rodríguez 1995: 401). Tras embarcar en Algeciras, llegaron a Ceuta y de allí pasaron por Tetuán, Tánger, Arcila, Larache, donde se encontraron con Montalbán, director de las excavaciones en Lixus, Alcazarquivir, Rabat, Casablanca, Marrakesh, Rabat ya de vuelta, Mequínez, Muley Idris, las excavaciones de Volubilis, Mequínez, Fez, Larache, Tetuán y Ceuta (Gómez-Moreno Rodríguez 1995: 402-406).

\section{CONSERVADOR DEL MUSEO ARQUEOLÓGICO NACIONAL}

Con el nombramiento de Álvarez-Ossorio y Farfán de los Godos como Director del Museo Arqueológico Nacional (MAN) y la entrada de Gómez-Moreno como Director General de Bellas Artes el 1 de febrero de 1930 (Gómez-Moreno Rodríguez 1995: 388 ), se produjo el inicio de un importante cambio en el MAN, pues de los 27 aspirantes por oposición al Cuerpo Facultativo de Archiveros, Bibliotecarios y Arqueólogos, cuatro ingresaron en el MAN. En el tribunal, Gómez-Moreno, que era vocal, pasó a presidirlo al ser nombrado Director General, cediéndole la presidencia Francisco Rodríguez Marín, el 14 de marzo de 1930, el anterior presidente que por su nuevo cargo lo consideraba un superior jerárquico (IGM 15.188). La constitución del tribunal se efectuó el 13 de mayo (IGM 15.514).

Los cuatro nuevos miembros destinados "en prácticas" como Asistentes por oposición, con sueldo anual de 4.000 pesetas, según orden del 2 de julio de 1930 (Gaceta de Madrid del 8 de julio), firmada por GómezMoreno, fueron Emilio Camps Cazorla ( $n^{\circ} 4$ de la oposición), Felipe Mateu y Llopis ( $\left.n^{\circ} 7\right)$, Felipa Niño y Mas $\left(n^{\circ}\right.$ 9) y Luis Vázquez de Parga Iglesias (AMAN EP ECC 1-2; AGA 31/4643).

Tomó posesión el 11 de julio, pero ya cesó el día 27, para ser nombrado el 4 de agosto de 1930 como funcionario facultativo con sueldo de 5.000 pesetas, tomando posesión al día siguiente, junto con Mateu y Niño (AMAN EP ECC 7-8; AGA 31/4643). No obstante, su adscripción siguió siendo "para verificar prácticas al Museo Arqueológico Nacional” según Real Orden de 28 de agosto (AMAN EP ECC 9), ascendiendo su sueldo a 6.000 pesetas el 12 de febrero de 1931 (AMAN EP ECC 13; AGA 31/4643). Por Orden Ministerial de 20 de junio de 1931 se abrió un concurso de méritos para plazas vacantes en el MAN. Según indicaba, junto con Felipa Niño y Luis Vázquez de Parga, habían catalogado e inventariado los materiales arqueológicos de las excavaciones de los valles del Manzanares y del Jarama (Madrid) dirigidas por Paul Wernert y José Pérez de Barradas, las del Cerro del Berrueco (Medinilla, Ávila-El Tejado-Puente Congosto, Salamanca) dirigidas por César Morán Bardón, las de Bilbilis (Huérmeda, Zaragoza) de Narciso Sentenach, las de Roquizal del Rullo (Fabara, Zaragoza) de Pérez Temprado, las de Baelo Claudia (Bolonia, Cádiz) por Pierre Paris, y la colección de Ibiza de Vives, la egipcia de Francisco Roque Martínez y la numismática de 
Castellanos de Losada (AMAN EP ECC 17). Una de las plazas le fue concedida a Camps según Orden Ministerial de 24 de julio de 1931, tomando posesión el 1 de agosto (AMAN EP ECC 19). Tuvo un ascenso salarial a 7.000 pesetas anuales el 25 de noviembre de 1934, tomando posesión el 3 de diciembre (AMAN EP ECC 24; AGA 31/4643).

Su principal función entre 1933-36 fue la ordenación, instalación y estudio de la sala de cerámica hispano-musulmana del MAN, y con la ayuda de otros conservadores, también de la cerámica de Talavera de los siglos XVI-XVIII, y otras cerámicas del siglo XVIII, en particular de la fábrica de Alcora y de la fábrica del Buen Retiro, nuevas salas de exposición que se pensaban inaugurar en junio de 1936 (AGA 31/4643; Álvarez-Ossorio 1936; Camps 1936).

\section{EL VIAJE A ITALIA Y FRANCIA DE 1930 CON NAVASCUÉS Y TARACENA}

Aprovechando su nuevo cargo de Director General de Bellas Artes, uno de los objetivos de Gómez-Moreno fue potenciar la carrera científica de Camps, Navascués y Taracena. Para ello, estableció una convocatoria a la que podían optar 3 funcionarios del Cuerpo Facultativo de Archiveros, Bibliotecarios y Arqueólogos para "especializarse en el extranjero", según Real Orden de 20 de agosto, aprovechando una partida económica que existía, por la cual 5 "oficiales arqueólogos” podían realizar comisiones en el extranjero con una ayuda de 3.250 pesetas por cada semestre, que aumentó hasta 5.750 pesetas con la reducción a tres posibles solicitantes, concedida el 16 de septiembre de 1930 (AMAN EP ECC 10). Para que se ajustasen a la convocatoria, Camps y Navascués fueron nombrados representantes del MAN en la Conferencia Internacional de Museos de la Sociedad de las Naciones que iba a celebrarse en Roma entre el 13 y el 17 de octubre de 1930, a la vez que el viaje tenía como objetivo, en el caso de Camps, que visitase museos de Italia, Sicilia y Francia con "especial interés a los fondos de la primera Edad Media y de la dominación árabe" (AMAN EP ECC 17).

El viaje a Italia y Francia partió de Madrid (1-10), Zaragoza (1-10/2-10), Tarragona (2-10/3-10) y Barcelona (4-10) en España, siguió por Nimes (4-10/5-10), Orange (6-10), Arlés (6-10/7-10) y Marsella (7-10) en Francia, Génova (8-10/10-10), Pisa (10-10), Roma (11-10/1-11, 13-11), Asís (29-10), Nápoles (1-11/511), Pompeya (6-11, 12-11), Paestum (7-11), Palermo (8-11/10-11), Cefalú (11-11), Florencia (13-11/18-11),
Fiésole (16-11), Siena (19-11), Pisa (20-11), Bolonia (20-11/21-11), Rávena (22-11), Venecia (22-11/26-11), Padua (27-11), Verona (27-11/28-11), Milán (28-11, 30-11/2-12), Turín en Italia (29-11) y París (3-12/1612), regresando de vuelta a Madrid (Camps 1930/2015; Salve y Espinós 2015).

En Roma, junto con Navascués y Taracena asistió a la Conferencia Internacional para el estudio de los Métodos Científicos aplicados al Examen y a la Conservación de Obras de Arte en Roma en 1930, International Conference on the Examination and Preservation of Works of Art, el primero convocado por la Organización Internacional de Museos, que se celebró entre el 13 y el 17 de octubre, a cuya finalización el día 18, Camps (1930/2015: 86-93) comenta que ya estaban "libres de pesadillas de Congreso".

Camps y Navascués eran católicos practicantes regularmente y nada más llegaron a Francia en Nimes y otras ciudades buscaban una iglesia donde asistir a misa (Camps 1930/2015: 61, 316), confesando y comulgando habitualmente (Camps 1930/2015: 153), e incluso visitando al Papa Pío XI (Camps 1930/2015: 154-155).

Lo primero que ambos hicieron al entrar en Francia fue escribir a "don Manuel” Gómez-Moreno y a Álvarez-Ossorio, y además Camps lo hizo a "don Ricardo" Velázquez Bosco (Camps 1930/2015: 65, 278). Gómez-Moreno fue informado regularmente del viaje por Camps, y también le contestaba sus cartas (1930/2015: 109 n. 64, 152, 219, 294).

Con 10 días ya en Roma, la diferente orientación investigadora de Camps y Navascués respecto a Taracena se refleja cuando el día 25 fueron a visitar Santa María in Aracoeli en Roma, mientras Taracena se fue al Museo Prehistórico (Camps 1930/2015: 116). Previamente los tres habían hecho un intento el día 20, pero estaba cerrado (Camps 1930/2015: 102).

\section{EL CRUCERO UNIVERSITARIO POR EL MEDITERRÁNEO DE 1933}

Dos de ellos, Camps y Taracena, también participaron en el Crucero Universitario por el Mediterráneo. Camps solicitó un permiso de ausencia desde el 15 de junio hasta fines de julio de 1933 (AMAN EP ECC 23).

La salida fue de Barcelona a las 4 de la tarde del 15 de junio, Túnez-Cartago (17-6), Susa-Kairuán, Túnez (18-6), La Valette, Malta (19-6), Alejandría-El Cairo (22-6), El Cairo (22-6/24-6), El Cairo-Alejandría (256), Jaffa, Israel (26-6), Jaffa-Jerusalén (27-6), Jerusalén 


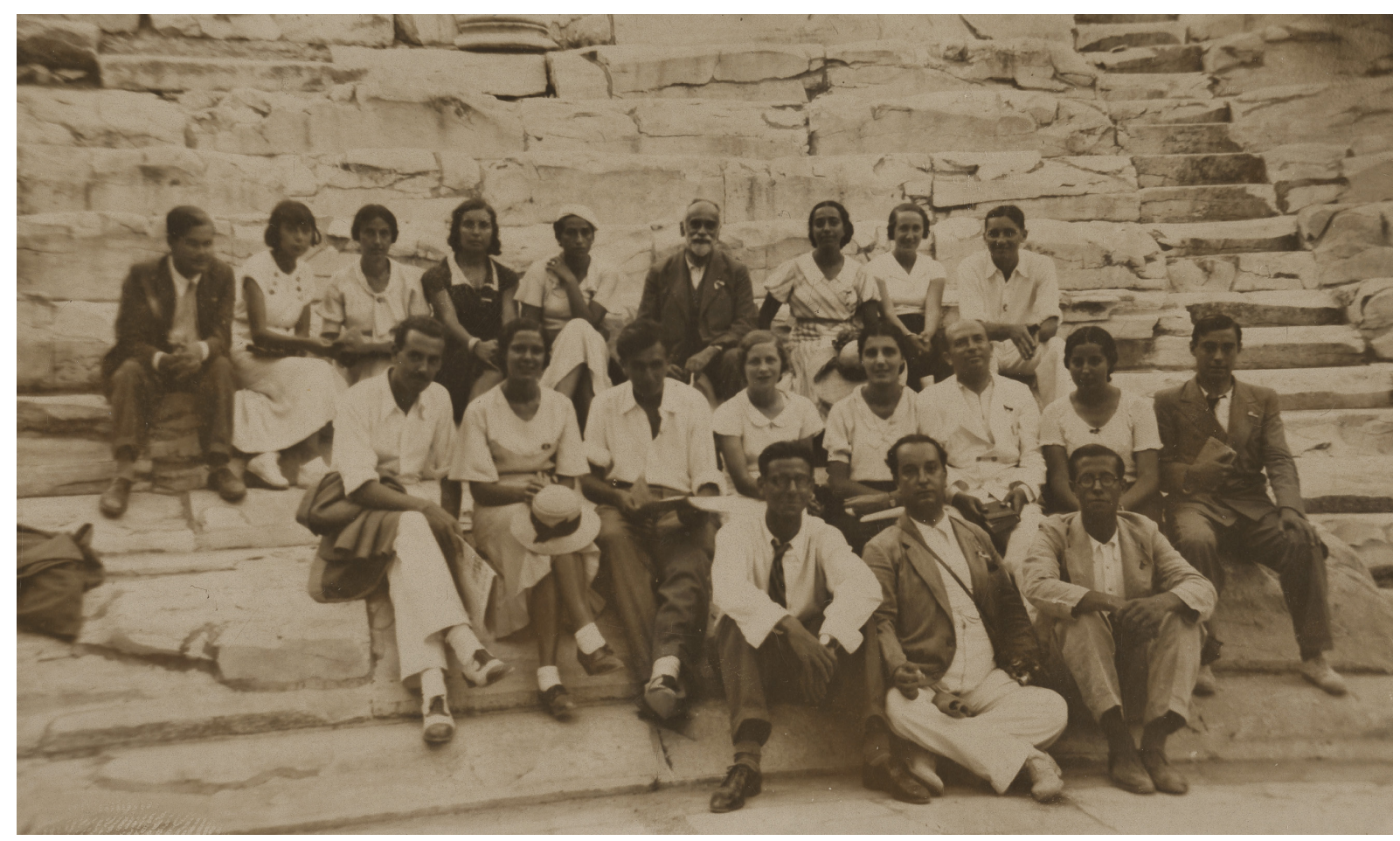

Figura 1. Crucero del Mediterráneo, junio-julio de 1933. En la fila superior, Manuel Gómez-Moreno. En la media, Encarnación Cabré y Cayetano de Mergelina. En la inferior, Emilio Camps. CeDAP UAM. Legado Cabré. Álbum Crucero 3 nº 603.

(28-6), Jerusalén-Jaffa (29-6), La Candia, Creta (1-7), Knossos-La Candia (2-7), Rodas (3-7), Esmirna (47/5-7), Constantinopla, Turquía (6-7/10-7), Salónica, Grecia (11-7/13-7), Atenas (14-7/16-7), Nauplia-Micenas-Tirinte (17-7), Itea-Delfos (18-7), Catácolo-Pyrgos-Olimpia (19-7), Siracusa, Sicilia (20-7/21-7), Palermo, Sicilia (22-7/23-7), Nápoles (24-7), Pompeya-Herculano (25-7), Paestum-Salerno (26-7), Nápoles (27-7/28-7), Mahón, Menorca (30-7), Palma de Mallorca (31-7), Valencia (1-8) (Gómez-Moreno Rodríguez 1995: 408-409; Gracia y Fullola 2006: 80-81). (figs. 1-2).

En el crucero, durante el segundo día de viaje, el 16 de junio, en ruta hacia Túnez, se dieron varias conferencias, algunas sobre arqueología como la de Mergelina sobre Cartago, mientras otras fueron más de Historia del Arte como la de Tormo con una visión general sobre los monumentos del país, la de Camps sobre Túnez y Susa o la de Gómez-Moreno de Kairuán (Gómez-Moreno Rodríguez 1995: 412; Gracia y Fullola 2006: 104). En el barco, en una mesa del comedor de primera clase, presidida por el capitán, Jaume Gelpí y Gómez-Moreno, se sentaban Mergelina, Carriazo, Camps, María Elena Gómez-Moreno, una amiga suya del doctorado procedente de Granada, Elena Rodríguez Danilewsky y Antonio Tovar, alumno de Mergelina en Valladolid (Gómez-Moreno Rodríguez 1995: 411).

\section{EXCAVACIONES EN SANCHORREJA Y CASTILTIERRA}

La formación arqueológica de Camps se hizo en campañas con Cayetano de Mergelina y Juan Cabré. Participó por primera vez, al licenciarse en el curso 1924-25, en la campaña que realizó Mergelina en 1925 en los dólmenes de la necrópolis de Montefrío (Morelabor, Granada) (AGA 31/4643), pero no en la que hizo en 1926 (AGA 32/13.362; Mergelina 1941-42: 33, 1945-46).

Continuó en la excavación de la necrópolis ibérica y la cámara funeraria de Toya en el Cerro de la Horca (Peal del Becerro, Jaén), frente a la población de Tugia, entre julio y agosto de 1927, donde también participaron Rafael Laínez y Juan de Mata Carriazo (AGA 31/4643; Cabré 1925; Mergelina 1943-44; Laínez 1953: 95).

En el castro de Las Cogotas (Cardeñosa, Ávila), Cabré comenzó sus excavaciones en 1927, y en la segunda campaña de 1928 contó con la participación de Camps 


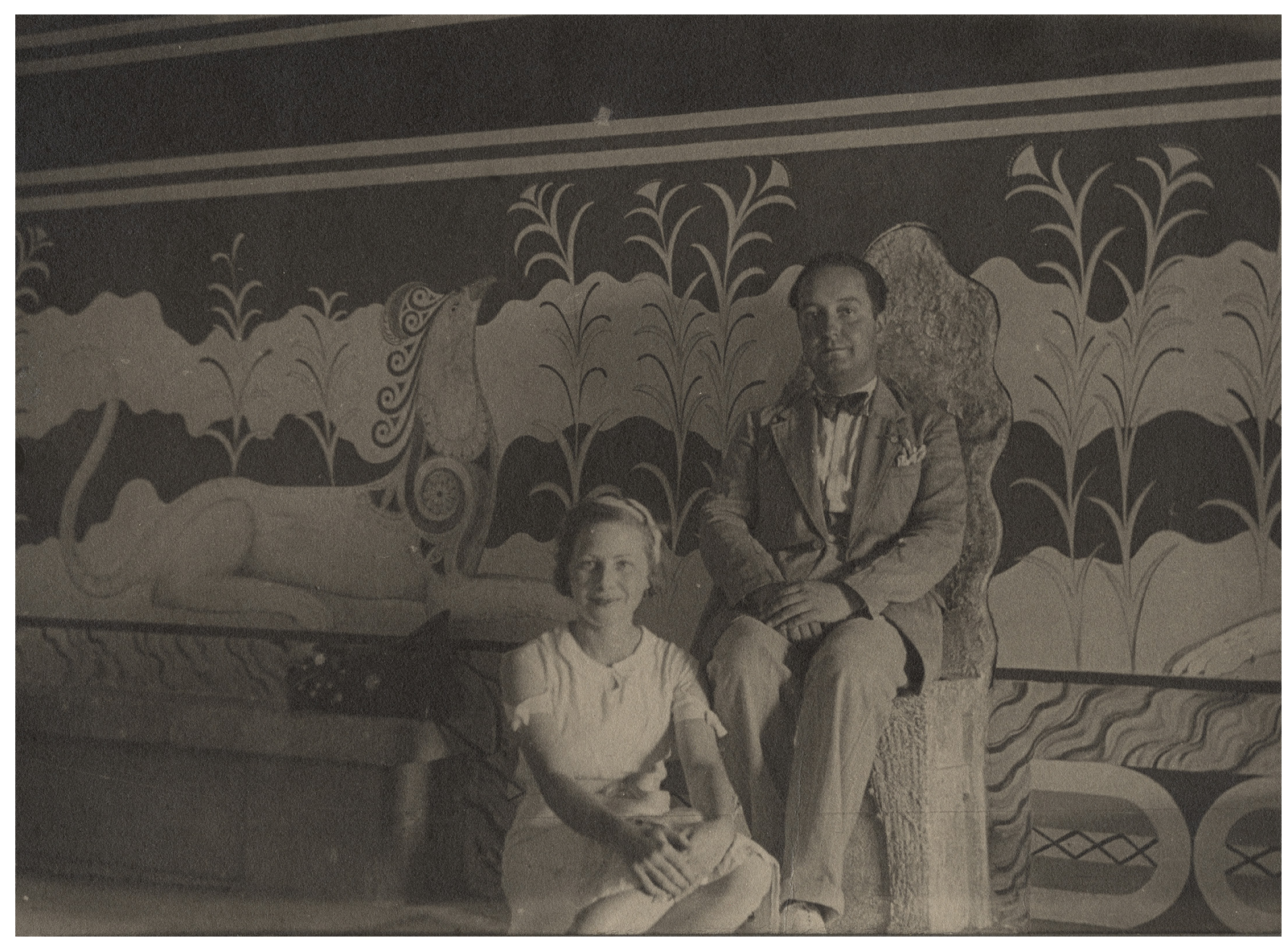

Figura 2. Crucero del Mediterráneo, 2 de julio de 1933. Emilio Camps en el trono del palacio de Knossos (Creta) con Encarnación Cabré. CeDAP UAM. Legado Cabré. Álbum Crucero 2 nº 492.

(AGA 31/4643), pero no participó en las dos siguientes, en particular la de 1930 cuando se localizó la necrópolis (Cabré 1932).

Ese mismo año se incorporó a la primera campaña de excavación en el castro de la Edad del Hierro de la Citania de Santa Tecla (La Guardia, Pontevedra) (AGA 31/4643), realizada en 1928, financiada por la Diputación Provincial de Pontevedra, continuando las excavaciones precedentes de Ignacio Calvo, si bien no participó en la de 1929, ni en la de 1932 (AGA 32/13.362; Mergelina 1944-45). Durante la campaña de 1928 les visitó Gómez-Moreno en la casa veraniega que Mergelina había alquilado para su familia en La Guardia, donde se quedaban su mujer y los tres hijos pequeños (Gómez-Moreno Rodríguez 1995: 358).

La última campaña en la que figura como colaborador fue la de 1930 en el yacimiento ibero-romano del Cabezo de Alcalá en Azaila (Teruel) (AGA 31/4643), que excavaron conjuntamente Cabré y Lorenzo Pérez Temprado entre 1919-32 (Beltrán Lloris 1995, 2012-13).
Ese año se vio involucrado en el proceso de desmontaje de la iglesia visigoda de San Pedro de la Nave (Zamora) porque iba a quedar bajo las aguas por una presa del río Esla. En agosto de 1930 realizó excavaciones previas a su traslado (AGA 31/1505) en las sepulturas del interior de la iglesia e identificó otras posibles edificaciones inmediatas (Camps 1940: 540-571, 1940-41). $\mathrm{Su}$ posterior reconstrucción se alargó hasta febrero de 1932, dirigida por el arquitecto Alejandro Ferrant, que estaba entonces trabajando en Marruecos, bajo la supervisión final de Gómez-Moreno, entonces Director General de Bellas Artes, que la había estudiado en el Catálogo Monumental de Zamora, identificándola por primera vez como visigoda (Gómez-Moreno Rodríguez 1995: 390). El éxito del traslado a $2 \mathrm{~km}$ propició el nombramiento de Ferrant como arquitecto de la Primera Zona Monumental o antiguo reino de León y Galicia (Gómez-Moreno Rodríguez 1995: 391).

Las excavaciones del Castro de los Castillejos (Sanchorreja, Ávila), fueron dirigidas por Juan Cabré, 
Joaquín María de Navascués y Emilio Camps en la primera campaña de 1931, y luego las continuaron Navascués y Camps entre 1932-35, Órdenes Ministeriales de 27 de junio de 1932, 5 de abril de 1933 y 13 de julio de 1935 (AGA 42/5291), aunque la dirección de las campañas de 1932 y 1933 se ha atribuido por confusión a Cabré (Arias y Balmaseda 2016: 31 n. 146, 34 n. 161). El yacimiento fue descubierto en 1929 por el catedrático de Historia de España de la Universidad de Madrid desde 1920, Claudio Sánchez Albornoz, quien realizó una primera excavación en 1930 junto a la muralla (Maluquer 1958: 1, 23 fig. 3). En 1931, siendo ya Decano de la Facultad de Filosofía y Letras, asumió los trabajos la Junta Superior de Excavaciones quien designó para la primera campaña a Cabré, Navascués y Camps, donde destacó el descubrimiento de un depósito de bronces que incluía un broche de cinturón "tartésico" (Maluquer 1957: 242-249 fig. 1-3, 1958: 7-8). En agosto de 1932 y en septiembre de 1933 se realizaron 2 campañas, de las que se conservan los diarios que fueron utilizados por Maluquer (1958: 2, 23 fig. 3). Con seguridad sabemos que Navascués y Camps partieron para la segunda excavación el 25 de julio de 1932 (AGA 42/5291) y acabaron el 28 de agosto, ese mismo día ya se desplazaron a Castiltierra (AMAN 1955/51 98). En 1933 una nota manuscrita nos indica que las fechas fueron entre el 31 de julio y el 2 de septiembre (AMAN 1955/51 98). En la denominada campaña de 1934 el objetivo fue la localización de la necrópolis al exterior del poblado, pero no se consiguió identificarla, de la que sólo se conservaron las fotografías después de la Guerra Civil (Maluquer 1958: 2-3, 8-9). También en otro trabajo cita la campaña en 1935 (Maluquer 1957: 241 n. 1). Pero ambas deben corresponder a la campaña de 1935 .

Los materiales de las excavaciones fueron cedidos por Navascués a Maluquer (1957: 241 notas 1-2, 1958: 3) que había figurado en el tribunal de su cátedra como secretario de la oposición en marzo de 1950 (AGA 31/4009).

Ya desde la campaña de 1932, al excavar la cabaña "de los bronces" o Sa 1, a extramuros de la acrópolis, se advirtió que el yacimiento presentaba un nivel inferior con cerámicas excisas y de boquique de tipo Cogotas I, y uno superior con cerámicas pintadas y otras impresas a peine de tipo Cogotas II, procediendo los bronces de la parte superior del nivel inferior (Maluquer 1958: 8-9, 29 fig. 5), localizándose 7 cabañas, Sa 1 a Sa 7 (Maluquer 1958: 28). Durante la campaña de 1933 se excavó a la derecha de la puerta principal de la acrópolis localizándose la planta de 8 cabañas, de Sa 8 a Sa 17
(Maluquer 1958: 9, 28). El trabajo de buen dibujante de Camps se observa en la planta del poblado (Maluquer 1958: 23 fig. 3) o en los dibujos de la estratigrafía señalándose los distintos niveles (Maluquer 1958: 17 fig. 1).

La necrópolis visigoda de Castiltierra (Segovia) había sido sistemáticamente expoliada, citándose en 1931 unas 500 tumbas (Martínez Santa-Olalla 1931: 57), cifra que Arias y Balmaseda (2016: 19) no consideran exagerada. Tras una petición formal de excavaciones por parte de la Comisión Provincial de Monumentos de Segovia, se acordó el 10 de mayo de 1932 el inicio de las mismas, concediéndoles 7.500 pesetas y designándose a Camps y Navascués como sus directores (Orden Ministerial de 27 de junio). La campaña se realizó del 20 de septiembre al 1 de octubre de 1932, durante 11 días, donde estuvo presente en exclusiva Camps según su diario de excavaciones, documentándose 65 tumbas (Arias y Balmaseda 2016: 31), pero estuvieron preparando la excavación y quizás estudiando materiales de excavaciones previas del 28 de agosto al 2 de octubre (AMAN 1955/51 97). La segunda campaña abarcó entre el 6 y el 26 de septiembre de 1933, durante 21 días, de los cuales hubo 16 días de trabajo de campo, localizándose 172 sepulturas (de la 69 a la 243), siendo el diario llevado por Camps (Arias y Balmaseda 2016: 33-34), con 6.000 pesetas de financiación (Orden Ministerial de 5 de abril), aunque ellos permanecieron en el yacimiento entre el 3 de septiembre y el 1 de octubre (AMAN 1955/51 15). En la tercera campaña, el libramiento del dinero fue muy tardío, que no fue retirado hasta el 23 de noviembre, también 6.000 pesetas de financiación (Orden Ministerial de 16 de agosto de 1934), por lo que planificaron la campaña entre el 3 y el 30 de diciembre. Según la propuesta de Arias y Balmaseda (2016: 35), a partir del diario que pone Castiltierra 1934-1935, un borrador de las jornadas de 37 trabajadores con la fecha de 1935 y un oficio del alcalde del 18 de diciembre de 1935, se usó la consignación de 1934 en la campaña de finales de octubre y la primera quincena de noviembre de 1935, con las tumbas de la 244 a la 343 en el diario I y de la 354 a la 459. Sin embargo, algo pasó durante la campaña porque los dibujos de Camps sólo llegan hasta la sepultura 312, faltando a partir de entonces muchos dibujos o indicaciones (Arias y Balmaseda 2016: 29, 35). Sus descripciones de tumbas finalizan en la 315 , y sólo se reanudan entre la 359 y la 384, siendo Navascués quién excavó todas las últimas entre la 385-459 (Arias y Balmaseda 2016: 29 n. 133), por lo que es posible que Camps faltase en el final de la campaña, lo que pudo afectar a la documentación, ya que era quien habitualmente 
llevaba esta parte de la excavación. En todo caso, Navascués cuando cita el yacimiento sólo pone la codirección de las campañas de 1933-34 (AGA 42/5291), pues no asistió a la breve campaña de 1932, y podría pensarse que entonces no hubo campaña en 1935. Tal vez el problema venga por la justificación de las cuentas de campaña que fue a finales del año siguiente. Hay un escrito del alcalde de 5 de diciembre de 1934 que indica que "Ante mí se han presentado" Camps y Navascués y ya "se hallan efectuando los trabajos" (AMAN 1955/51 35 y 48). Las dietas cobradas por ambos, cada uno 540 pesetas, corresponden al 3 y 30 de diciembre (AMAN 1955/51 38). Quizás el tratar de estar en casa el día de fin de año, aunque en principio pensaron permanecer algunos días de enero, podría justificar las fechas de la portada de los diarios 1934-35. También ayudaría a explicar parte de la precipitación del final de esta campaña y la ausencia de Camps durante los días de la Navidad (fig. 3).

Esta necrópolis, junto con la que estaba realizando Martínez Santa-Olalla (1933) en Herrera del Pisuerga (Palencia), fueron los trabajos punteros en arqueología visigoda en la época, pero el proyecto quedó paralizado con el estallido de la Guerra Civil.

\section{DOCTORADO E INTERRUPCIÓN DEL CONCURSO A LA CÁTEDRA DE ARQUEOLOGÍA MEDIEVAL EN 1936}

A inicios de 1935, Gómez-Moreno decidió retirarse de la Universidad, pues cumplía 65 años en febrero, aunque podía continuar hasta los 70, "por considerar fracasada su labor en la Ciudad Universitaria” (GómezMoreno Martínez 1951-58/1977: 59). Se acumulaban una serie sucesiva de derrotas personales. El carácter de Gómez-Moreno no era el adecuado para un alto cargo y tuvo muchos disgustos adicionales durante su periodo de Director General entre 1930-31: "me dicen que don Manuel anda muy mediano del estómago ¡Maldita Dirección [General de Bellas Artes] y malditas imbecilidades oficiales! Es la peor faena que la han podido hacer" (Camps 1930/2015: 309-310). Continuaron con la pérdida por Carriazo de la cátedra de Arqueología en la Universidad de Madrid en diciembre de 1931, que afectó notablemente a Gómez-Moreno, donde sólo consiguió su propio voto (Mederos 2010a: 65-66). Después estaba muy irritado por el traslado de las clases desde el curso 1933-34 a la nueva Ciudad Universitaria en Moncloa, cuya primera facultad en abrirse fue Filosofía y Letras, pues los alumnos y el propio Gómez-Moreno tenían que trasladarse por la tarde sin medios de transportes adecuados, y con insuficiente material docente como libros, fotos y diapositivas, lo que provocó la ausencia de los oyentes habituales y un drástico descenso del número de alumnos (Gómez-Moreno Rodríguez 1995: 465-466). Finalmente, estaba cada vez más incómodo por la evolución de los acontecimientos políticos, pues después de la Revolución de los mineros asturianos entre el 5 y el 19 de octubre de 1934, tuvo que participar en la restauración del Tesoro de la Cámara Santa de la catedral de Oviedo, que había sido dinamitada (Gómez-Moreno Martínez 1934; Gómez-Moreno Rodríguez 1995: 458-460).

La cátedra se convocó el 7 de octubre de 1935 (Gaceta de Madrid del 13 de octubre), y en la minuta del ministerio aparece tachada Arqueología Arábiga, y convertida en Arqueología Medieval (Cristiana y Árabe). El cambio había tenido que ser aprobado por el Consejo Nacional de Cultura, que lo aceptó el 30 de agosto de 1935, pero con "especialidad, siempre dentro de la Edad Media" (AGA/13.560/9575/9). Realmente ya lo aplicaba en su docencia el propio Gómez-Moreno, como recuerda su hija en el curso 1926-27, donde "nos había dado un curso, no de Arqueología Árabe, sino de Arqueología Medieval Española, con todas sus ramificaciones reticulares; el arte tardo-romano y el bizantino" (Gómez-Moreno Rodríguez 1995: 331). El mismo día de salir a concurso, el 7 de octubre, se indicaba que en el Doctorado de la Universidad de Madrid, la asignatura de Arqueología Arábiga tenía que sustituirse por la nueva de Arqueología Medieval (AGA/13.560/9575/9).

Previamente a la oposición, Camps pagó las tasas de lectura el 23 de octubre de 1935 y presentó su tesis doctoral, Arte hispano-visigodo: ensayo de síntesis, dirigida por Elías Tormo, el 24 de noviembre de 1935, que obtuvo la calificación de sobresaliente (AGUCM D-1963, 4; AGA/13.560/9575/9; AGA 31/4643). El tribunal estuvo compuesto por Elías Tormo como Presidente, Emilio Lafuente Ferrari como secretario y actuaron como vocales, Andrés Ovejero, José Ferrandis y Antonio García y Bellido (AGUCM D-1963, 4). Por ello firmó la plaza más tarde que otros candidatos. En 1939, después de la Guerra Civil, le fue concedido el premio extraordinario el 21 de octubre de 1939 (AGA 31/1505). Parte de la tesis fue publicada en el tomo III de la Historia de España de Espasa-Calpe en el capítulo "El arte hispanovisigodo. Las artes monumentales" (Camps 1940). No pagó las tasas del título de doctor hasta el 8 de junio de 1949, que finalmente recibió el 17 de enero de 1950 (AGUCM D-1963, 4). 
Figura 3. En el centro, Navascués, ÁlvarezOssorio y Camps durante la campaña de 1933 en Castiltierra (Segovia). MAN1955-51 FD0004045r-B.

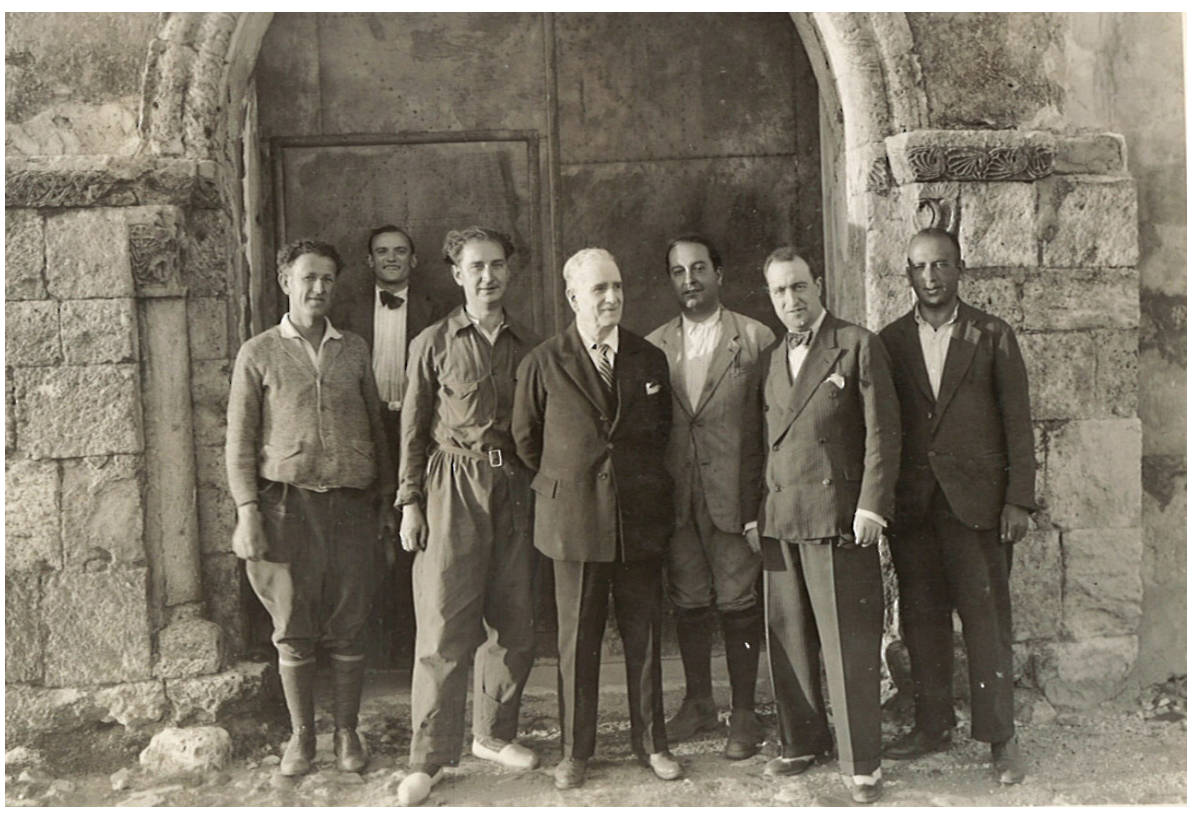

El tribunal fue designado el 27 de enero de 1936, presidido por Elías Tormo y Monzón, exconsejero de Instrucción Pública y catedrático de Historia del Arte de la Universidad de Madrid; Luis Gonzalvo Paris, catedrático de Arqueología de la Universidad de Valencia; Antonio García y Bellido, catedrático de Arqueología de la Universidad de Madrid; José Vicente Amorós i Barra, catedrático de Arqueología de la Universidad de Barcelona y José Ferrandis Torres, catedrático de Epigrafía y Numismática de la Universidad de Madrid (AGA/13.560/9575/9).

Como presidente suplente se eligió a Cayetano Mergelina y Luna, catedrático de Arqueología, Numismática y Epigrafía de la Universidad de Valladolid; Emilio García Gómez, catedrático de Lengua Arábiga de la Universidad de Granada hasta 1935, cuando ganó plaza en Madrid; y Antonio Gallego Burín, catedrático y Decano de la Faculta de Filosofía y Letras de la Universidad de Granada, quien renunció, siendo elegido Juan de Contreras y López de Ayala, Marqués de Lozoya, catedrático de Historia de España de la Universidad de Valencia (AGA/13.560/9575/9).

Cinco fueron los candidatos que firmaron la plaza, primero el zaragozano José Camón Aznar, con 37 años, doctor el 23 de marzo de 1925 y catedrático de Teoría de la Literatura y de las Artes de la Universidad de Salamanca desde el 28 de abril de 1927, que la firmó el 25 de octubre de 1935. Desempeñaba desde el 18 de abril de 1928, por acuerdo de la Facultad de Filosofía y Letras de la Universidad de Salamanca, Real Orden desde el 29 de febrero de 1928, como acumulada la cátedra de Arqueología, Numismática y Epigrafía, con sueldo adicional de 2.000 pesetas anuales (AGA 32/13.362; 21/20.417). Al menos en el curso 1934-35 debió cesar, porque volvió a acumularse esta cátedra de Arqueología, Numismática y Epigrafía, ya con una gratificación de 3.000 pesetas, el 27 de noviembre de 1935 (AGA 21/20.417).

Después el soriano Juan Antonio Gaya Nuño, con 23 años, doctor desde el 22 de enero de 1934, ArchiveroBibliotecario de la Diputación Provincial de Soria, que la firmó el 8 de noviembre de 1935. El tercero fue el sevillano Fernando Jiménez-Placer y Suárez, con 29 años, doctor el 28 de abril de 1933 y Profesor Ayudante de Historia Medieval en la Universidad de Madrid desde el curso 1933-34. El cuarto fue Camps, con 32 años, doctor el 29 de noviembre de 1935 y Profesor Ayudante de Arqueología Arábiga desde el curso 1928-29, que la firmó el 7 de diciembre de 1935, una vez leída su tesis doctoral. Finalmente, el pontevedrés Sebastián González García, con 27 años, doctor en febrero de 1934, Profesor Ayudante de Arqueología y Numismática o Numismática y Epigrafía de la Universidad de Santiago de Compostela desde el curso 1928-29, que la firmó el 11 de diciembre de 1935 (AGA/13.560/9575/9). La lista de opositores se publicó el 29 de enero de 1936 (Gaceta de Madrid de 6 de febrero), fijándose el inicio de la oposición el 25 de junio de 1936 (AGA/13.560/9575/9).

Antes de la oposición, Camps y González García tenían una experiencia docente similar, pero Camps contaba con la ventaja de desempeñar la ayudantía de la cátedra 
de Arqueología Arábiga desde hacía 8 años y tenía más edad, 32 frente a 27 años. Acababa de publicar dos trabajos notables, El arte románico en España (Camps 1935), considerado "modelo en su género" por Gómez-Moreno (1953: 8), y Cerámica española (Camps 1936), y había hecho una buena tesis doctoral (Camps 1940). Otros trabajos suyos están centrados en la descripción de piezas adquiridas por el Museo Arqueológico Nacional (Camps 1931, 1932, 1932-33a y b) o de tejidos recuperados en las excavaciones de Castiltierra (Camps 1934). Por otra parte, tenía como presidente de la oposición al director de su tesis doctoral, exrector y exministro de Instrucción Pública y Bellas Artes entre 1930-31; como valenciano, Tormo quizás contase con el voto de Luis Gonzalvo; también era el director de la tesis doctoral de García y Bellido y unos meses antes José Ferrandis y García y Bellido habían sido vocales del tribunal de la tesis doctoral de Camps.

Lógicamente, el profesor más experimentado era Camón Aznar, de 37 años, 9 años como catedrático, pero el mantener una especialidad en Arqueología Medieval no lo beneficiaba ya que tenía claramente un perfil de Historia del Arte. La lógica sugiere que en condiciones normales Camps hubiese obtenido la plaza. Es posible que Camón Aznar ya estuviese propugnándose para sustituir en la cátedra de Historia del Arte a Elías Tormo, que la detentaba desde 1903, pues en junio de 1936 cumplía 67 años, y sólo le quedaban 3 años de servicio en caso que quisiese continuar hasta los 70 años, o al menos, manifestando públicamente que seguía aspirando a una plaza en la Universidad de Madrid.

\section{LA GUERRA CIVIL}

Desde el inicio de la Guerra Civil, Camps fue declarado "cesante" el 9 de septiembre de 1936 por "desafecto al régimen" y haber "colaborado directa o indirectamente con la rebelión militar" según decreto del Ministro de Instrucción Pública y Bellas Artes, Jesús Hernández Tomás (AMAN EP ECC 51; AGA 31/6054/37; AGA 31/1505; Gaceta de Madrid del 10 de septiembre). A ello se unió que por el avance del frente de Madrid, tuvo que abandonar su vivienda en la calle Andrés Mellado el 8 de diciembre, que "fue saqueada concienzudamente" donde "perdió la mayor parte de sus materiales de estudio y trabajo, notas, fotografías, etc. y toda su modesta biblioteca personal, amén de todos los muebles, enseres y ropa" (AGA 31/6054/37).

Fue readmitido como disponible gubernativo el 20 de febrero de 1937, momento en que volvió a recibir 2/3 de su sueldo (AGA 31/6054/37). Para ello, poco antes tuvo que darse de alta, el 28 de enero, en el sindicato único de la enseñanza de la Confederación $\mathrm{Na}$ cional del Trabajo (CNT), aunque lo justificó con que necesitaba evacuar los muebles de su casa situada en la calle Andrés Mellado 34. En este tiempo estuvo trabajando como secretario del centro de pre-aprendizaje de la Federación Regional de Sindicatos de la Enseñanza del Centro, en la calle Manuel Silvela 4. Paralelamente, siguió cotizando hasta noviembre de 1938, si bien Camps fue vuelto a ser declarado cesante al negarse a hacer la evacuación forzosa hacia Valencia en octubre de 1937 (AGA 31/6054/37).

A partir de entonces su medio de subsistencia fue como profesor particular de bachillerato, para lo cual también se afilió a la Agrupación Profesional de Licenciados y Doctores en Ciencias y Letras, a la vez que trabajaba como secretario en el Instituto Ferrer de la CNT, en la antigua sección de párvulos del Colegio Alemán de la calle Rafael Calvo, ayudando desde allí "a numerosísimos elementos de la llamada "quinta columna", hasta la caída de Madrid (AMAN EP ECC 32-33; AGA 31/6054/37). Previamente fue movilizado el 12 de septiembre de 1938, pero logró ingresar en una unidad no combatiente (AGA 31/6054/37).

El Juzgado Militar de Funcionarios lo calificó de "carácter e ideología derechista". A su favor testificaron el 5 de mayo de 1939 los funcionarios del Museo Arqueológico Nacional Casto $\mathrm{M}^{\mathrm{a}}$. del Rivero, Felipe Mateu Llopis, Felipa Niño y Mas y Luis Vázquez de Parga, además de Julián Peris Mencheta quien señalaba que no podía opinar porque fue "detenido primero y [permaneció] oculto después". Unos testigos que Blas Taracena, aún como Inspector General de Museos, consideraba el 9 de mayo "de indiscutible solvencia política y moral" (AMAN EP ECC 33-35). Su absolución y admisión como funcionario "sin imposición de sanción" fue decidida por el juez militar y firmada por Javier Lasso, Jefe de Archivos y Bibliotecas, el 7 de agosto de 1939 (AMAN EP ECC 38).

\section{SECRETARIO DEL MUSEO ARQUEOLÓGICO NACIONAL, CANDIDATO A LA DIRECCIÓN, REINCORPORACIÓN A LA UNIVERSIDAD Y COLABORADOR DEL CSIC}

Antes de resolverse su expediente de depuración, Camps fue nombrado Secretario del Museo Arqueológico Nacional por Javier Lasso de la Vega y Jiménez-Placer, Jefe Nacional de Archivos, Bibliotecas y 
Registro de la Propiedad Intelectual, el 24 de abril de 1939 (AGA 32/1505). Fue casi inmediato después del nombramiento como director del MAN de Blas Taracena, el 3 de abril de 1939 (AGA 31/6056; AMAN EP BTA 1; Mederos 2015: 327) (fig. 4).

Después de su reincorporación fue ascendido a la $7^{\mathrm{a}}$ categoría con sueldo de 8.000 pesetas el 2 de octubre de 1939, tomando posesión el día 4 (AMAN EP ECC 40 y 44). Recibió mejoras salariales hasta 9.600 pesetas el 12 de enero de 1940 (AMAN EP ECC 47), ascenso a la $7^{\text {a }}$ categoría y 10.600 pesetas de sueldo el 13 de febrero de 1942 (AMAN EP ECC 55; AGA 31/4643) y a 12.000 pesetas el 5 de febrero de 1943 (AMAN EP ECC 57; AGA 31/4643). Su ascenso a la $6^{\text {a }}$ categoría se produjo el 10 de febrero de 1947, con sueldo de 16.000 pesetas (AMAN EP ECC 62; AGA 31/4643), año que se estableció una gratificación anual como Secretario del museo de 3.750 pesetas, desde el 8 de marzo (AMAN EP ECC 64; AGA 31/4643).

La relación entre Camps y Taracena había sido buena, aunque no sin discrepancias. La forma de ser de Taracena llevó a Camps a verter algunos juicios críticos sobre él por su carácter, pero siempre desde la amistad: "la pelmacería de Taracena" (Camps 1930/2015: 174), sus indecisiones (Camps 1930/2015: 175), su insatisfacción permanente por los constantes "reparos de Taracena, que siempre ha de estar descontento" (Camps 1930/2015: 312), su egoísmo pues es "una monada de niño, que no ve más que lo suyo y puesto a hacer guarraditas, las empalma que da gloria" (Camps 1930/2015: 299), su egolatría -“Don Blas" (Camps 1930/2015: 311)-, la falsa seguridad de "Taracena (...) [que] está efectivamente malo, preocupado con la conferencia, y empieza otra vez con los sudores (...) y con la falta de apetito y las imbecilidades de siempre" (Camps 1930/2015: 315), o su gusto por las mujeres que le lleva a estar con "una princesa" en el Foro romano "y a poco lo meten en chirona" (Camps 1930/2015: 121, 282, 314). No obstante, asume la independencia de Taracena, "él no tiene ninguna obligación de darnos cuenta de sus actos y lleva catorce años de vida independiente". Lo que más le preocupaba es que "don Manuel [GómezMoreno] no piense si nos habremos peleado, que es lo que a mí me importa" (Camps 1930/2015: 305).

En 1940 “compitieron" por la dirección del Museo Arqueológico Nacional. La edad reglamentaria de jubilación del anterior director, Francisco Álvarez-Ossorio y Farfán de los Godos, después de su jubilación forzosa en febrero de 1937 (AMAN EP FAOFG 34), se cumplía el 11 de septiembre de 1939. Teniéndolo en cuenta, el Director General de Archivos y Bibliotecas,

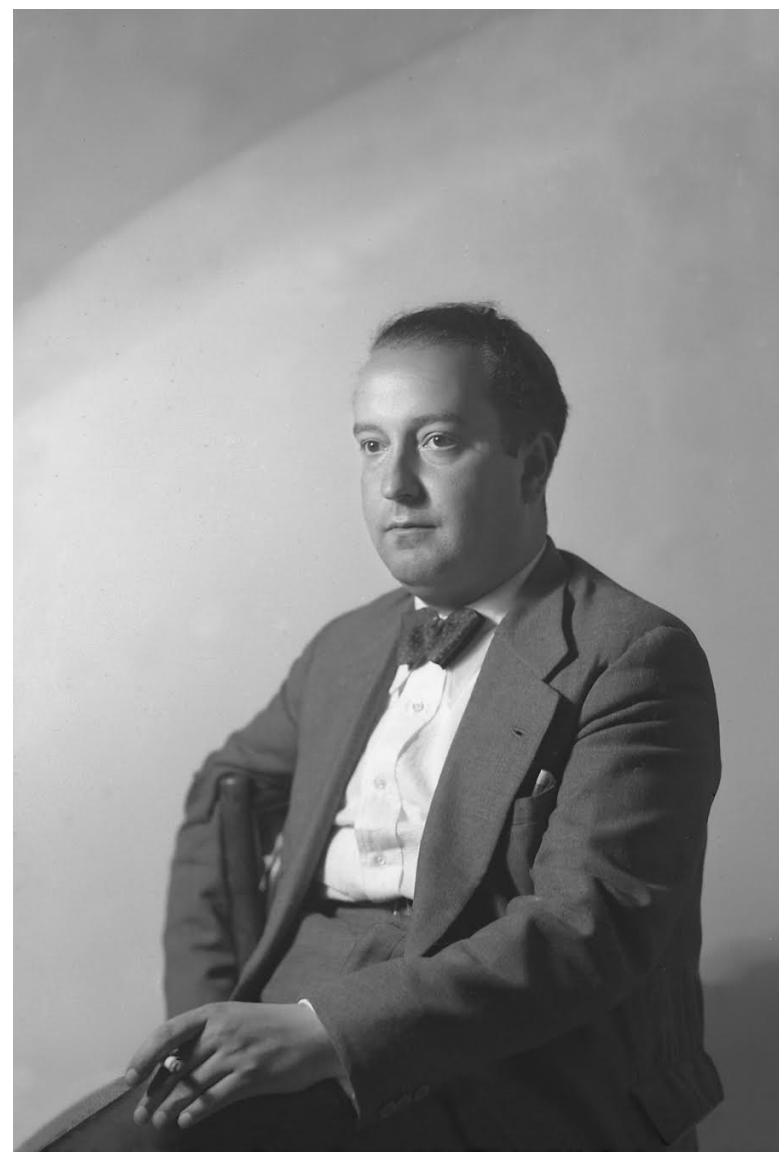

Figura 4. Emilio Camps, recién nombrado secretario del Museo Arqueológico Nacional, ca. 1939-40. MAN-FD/N/01433.

Miguel Artigas, planificó con Taracena su renuncia temporal al cargo para aumentar la pensión de Álvarez-Ossorio, al que ya se le había subido el sueldo el 14 de agosto de 1939 hasta 12.500 pesetas (AMAN EP FAOFG 51). Para conseguirlo, el 6 de septiembre, Taracena presentó su dimisión como director "con la más fervorosa adhesión a la obra y persona del Caudillo" (AMAN EP BTA 3). Así, el día 9 de septiembre, al estar vacante el cargo de Director, Álvarez-Ossorio se reintegró en su antiguo puesto con sueldo de 15.000 pesetas, (AMAN EP FAOFG 55). Tomó posesión el día 10 de septiembre y al día siguiente se produjo su jubilación "por cumplir la edad reglamentaria". Lo lógico es que un nuevo nombramiento de Taracena hubiese sido inmediato, pero este se retrasó casi 6 meses, hasta el 4 de marzo de 1940 (AMAN EP FAOFG 52 y 61; AMAN EP BTA 10; Mederos 2015: 328-329).

Las presiones para separar la dirección del museo de la inspección general de museos arqueológicos 
provinciales propiciaron que se abriera un concurso para optar al cargo, al que se presentaron cuatro candidatos: el director accidental, jefe de la sección de Numismática y funcionario de más antigüedad, Casto María del Rivero y Sainz de Baranda, Blas Taracena, Joaquín María de Navascués y Emilio Camps. Ya antes de la reunión del Patronato del Museo Arqueológico Nacional, el 11 de enero de 1940, el Director General de Archivos y Bibliotecas, Miguel Artigas, a través de un informe previo de la Junta Técnica, propuso la necesidad de separar los cargos de director del $\mathrm{Mu}$ seo Arqueológico Nacional y el de Inspector General de Museos, que hasta la dimisión de Taracena habían estado vinculados a la misma persona. En la reunión del Patronato, mientras Artigas "no se pronunció", fue la propuesta que también defendió el Director General de Bellas Artes, Juan Contreras y López de Ayala, Marqués de Lozoya, pues debería tenerse "en cuenta la situación actual del Museo Arqueológico Nacional totalmente desmontado durante la etapa roja (...) [con] un abrumador trabajo de reinstalación y reorganización de fondos". Los restantes patronos, el Conde de Casal como presidente, Álvarez-Ossorio como vicepresidente, José Ferrandis como secretario accidental, Antonio García y Bellido, Julio Martínez Santa-Olalla y Francisco Javier Sánchez Cantón, indicaron estar "todos de acuerdo que el director del museo se consagre totalmente a la reorganización del mismo (...) y que resulta incompatible con los desplazamientos". Como resultado, Taracena consiguió volver a ser reelegido director con el voto unánime, salvo la abstención anunciada de Artigas (AMAN Libro Actas Patronato $\mathrm{n}^{\circ} 84$, p. $\left.6 \mathrm{v}-7 \mathrm{v}\right)$; Navascués fue nombrado Inspector General de Museos el 4 de marzo de 1940 (AMAN EP JMNJ 29), el mismo día que Taracena lo fue como director del Museo Arqueológico Nacional (AMAN EP BTA 10); y para Casto María del Rivero, en compensación, también "por unanimidad", se propuso su nombramiento como miembro del Patronato, aunque esto nunca lo llevó a cabo el Ministerio. Camps, como puede observarse, en esta ocasión no tenía opciones y al presentarse en la terna probablemente beneficiaba a Navascués y Taracena, porque así Rivero no era el único excluido.

Uno de los primeros objetivos de Taracena y Camps fue incorporar a Juan Cabré al Museo Arqueológico Nacional (FD [Fondo Documental Pérez de Barradas] 2005/1/17 p. 152, 1-9-1939), que fue incluido en el pacto que realizó con Pérez de Barradas, director del Museo Antropológico Nacional, de tal forma que "vendrá al antro[pológico] todo lo etnológico -salvo arqueología americana- a cambio de la sección prehistórica y Cabré” (Mederos 2015: 328).

Por otra parte, Camps fue destinado el 17 de septiembre de 1940, Orden Ministerial del 20 de agosto, junto con Felipa Niño, a colaborar a tiempo completo para una exposición de Artes Decorativas, principalmente orfebrería y ropas eclesiásticas, "consecuencia de las incautaciones durante la guerra", organizada por el Servicio de Defensa del Patrimonio, a solicitud de Navascués (AMAN EP ECC 48; AGA 31/4643; Camps 1941c).

Hasta 1941, su principal ocupación junto con el director, Blas Taracena, fue la reorganización del museo después de su embalaje durante la Guerra Civil y la instalación de las exposiciones temporales del "museo abreviado". Una vez abierto se dedicó a la reinstalación de las salas de cerámica, que habían sido previamente preparadas para su inauguración en junio de 1936, con la reapertura de 5 salas el 17 de abril de 1942 con cerámica hispano-árabe, morisca y moderna, además de una nueva sala de porcelanas extranjeras (Camps 1943c), trabajos que continuaron hasta 1944 (AGA 31/4643). Dentro de las charlas paralelas a la inauguración, Camps impartió una conferencia sobre "La cerámica morisca" el 10 de junio de 1942, a la que asistieron el Director General de Bellas Artes y el embajador de Japón ( $A B C$ 11-6-1942: 12).

En la Universidad de Madrid, el 18 de octubre de 1939, Camps se reincorporó a su puesto de Ayudante de Clases Prácticas de Arqueología, y 3 días después, el 21, fue también nombrado Profesor Encargado de Curso de Arqueología Medieval con sueldo de 3.000 pesetas. Fue renovado al año siguiente como Encargado de Curso de Arqueología Arábiga el 31 de octubre de 1940, indicativo que no se había decidido un perfil definitivo a la plaza (AGA 32/1505).

Un tercer ingreso adicional lo consiguió con su entrada como Colaborador del Instituto Diego de Velázquez de Arte y Arqueología, en la sección de Arqueología Medieval que dirigía el Marqués de Lozoya. Fue nombrado el 18 de mayo de 1940, tomando posesión el 7 de junio, con un sueldo adicional de 3.000 pesetas (AGA 32/1505).

\section{LA CÁTEDRA DE HISTORIA DEL ARTE MEDIE VAL DE 1941}

Al no resolverse la cátedra de Arqueología Medieval en 1936, cuando volvió a ser convocada después de la Guerra Civil, el Ministerio decidió un cambio importante al no denominar ya la plaza como de Arqueología 
Medieval, sino como de Arte Medieval, lo que debilitó significativamente la posición de Camps.

La plaza fue convocada el 3 de junio de 1941 (BOE del 10 de junio) y la firmó primero Julio Martínez Santa-Olalla (AGA 31/1505), el mismo día de la publicación en el $\mathrm{BOE}$, indicativo que estaba informado de que se iba a convocar, pues detentaba la cátedra de Arqueología, Historia del Arte y Numismática de la Universidad de Santiago. Dos semanas después la firmó Camón Aznar, el 16 de junio (AGA 21/20.417). Casi dos meses después de ser convocada, el 31 de julio, lo hizo Camps (AGA 31/1505).

El proceso de firma de la plaza por José Camón Aznar fue el más complejo. Su problema principal fue que al permanecer en la zona republicana, fue suspendido de empleo y sueldo en la Universidad de Salamanca ya desde el 25 de noviembre de 1936 y su informe remitido a la Comisión Depuradora del Personal Universitario, presidida por el falangista y catedrático en Química General, Antonio de Gregorio Rocasolano, con sede en la Universidad de Zaragoza donde había sido Rector en 1929, que el 20 de enero de 1937 ordenó abrir expediente en contra suya. Aunque desde el Rectorado de Salamanca se indicaba que "no creo que merezca sanción alguna” (AGA 21/20.417), en la comisión había un miembro de la Universidad de Salamanca, el catedrático de Instituciones de Derecho Canónico, Teodoro Andrés Marcos, que quizás no le defendió suficientemente. La propuesta de la Comisión el 25 de febrero de 1937 fue de "separación definitiva del servicio y baja en el escalafón”, que fue aprobada el 20 de abril (AGA 21/20.417).

Ideológicamente, Camón Aznar había sido republicano, vinculado al Partido Radical Federal, dentro de la Alianza Republicana, presentándose con ellos en Salamanca en las elecciones de 1931 que encabezó, estando en tercera posición Miguel de Unamuno, y en las de 1933. Su baja se produjo en febrero de 1934 según declaró el 19 de febrero de 1939 (AGA 21/20.417).

El estallido de la Guerra Civil le sorprendió en la Universidad de Verano de Santander y una vez pasó a Francia no se unió a los sublevados, sino que se reincorporó a Madrid pues, según argumentaba, su mujer -realmente su futura mujer- María Luisa Álvarez se encontraba "completamente sola en Madrid, pues sus familiares se hallaban dentro del cerco de Oviedo" (AGA 21/20.417; Pallol 2014: 653). Esta fue la causa real de su dura sanción como señalaba el Juez instructor, que buscaba "los motivos por los que regresó a Madrid con la Universidad Internacional de Santander" (AGA 21/20.417), por no haber intentado pasarse a la zona nacional al pasar por Francia tras salir de Santander.

En Madrid, al negarse Camón Aznar a afiliarse a la Federación de Trabajadores de la Enseñanza de la Unión General de Trabajadores, dejó de percibir su salario entre noviembre de 1936 y abril de 1937 (AGA 21/20.417). Dos meses después, según el propio Camón Aznar, en enero de 1937, se afilió a la centuria Pizarro de Falange, y se encargaba de ayudar a los catedráticos de universidad destituidos (AGA 21/20.417; Pallol 2014: 653). Desde Madrid, en el verano de 1937, "en un autobús que pasaba por Valencia me fui a Barcelona (...) creí alejarme (...) del frenesí bélico que había en Madrid" (Camón Aznar 1984: 32-33).

Su presencia en Barcelona fue informada al Ministerio por el Rector-Comisario accidental y Decano de Farmacia, José Deulofeu Poch, quien indicaba que había quedado "agregado a las tareas de la misma", lo que fue autorizado por el Ministerio de Instrucción Pública y Bellas Artes el 14 de agosto y a recibir sus haberes en Barcelona (AGA 21/20.417).

Paralelamente, se integró en noviembre de 1937 en el grupo falangista J.M.B., ficha de afiliación " 3 a sección $n^{\circ} 3$, escuadra $2^{\mathrm{a}}$, falange $1^{\mathrm{a}}, 10^{\mathrm{a}}$ centuria" (AGA 21/20.417), la organización más importante de la Falange clandestina en Barcelona, cuyas siglas correspondían a las de su líder, el impresor Juan Manuel de Benito, colaborando desde diciembre en preparar una sublevación en el interior de Barcelona.

Sin embargo, sus miembros fueron descubiertos el 27 de enero de 1938 (AGA 21/20.417), al ser detenido su segundo miembro más importante, José López Pastor, oficial de notarías, que además llevaba encima el listado de los casi 1.000 miembros de la organización. La persona más significada que había incorporado el grupo J.M.B. era Rafael Sánchez Mazas, quien había llegado a Barcelona a finales de 1937 (Thomas 1992: 201). Era autor junto a José Antonio Primo de Rivera y el periodista Eugenio Montes (1957) de la idea de dar el nombre de Falange al nuevo partido y de la consigna Arriba España.

En la cadena de detenciones se detuvo a Sánchez Mazas y al doctor Fabián Isamat Vila que lo tenía refugiado. Con el doctor Isamat "vivía María Luisa", su futura esposa, "Yo iba allí todos los días" (Camón Aznar 1984: 33). Isamat declaró el 6 de febrero de 1939 que "en el proceso de alta traición y espionaje que se me siguió por este tribunal y en el que fui condenado a muerte figuraba José Camón como uno de los acusados de más relieve y culpabilidad". Lo mismo hizo la delegación provincial de Falange Española Tradicionalista 
y de las JONS de Barcelona certificando "que el camarada José Camón Aznar (...) era afiliado a F.E.T. y de las J.O.N.S., habiendo sido detenido y perseguido por las huestes del gobierno rojo-marxista y condenado a muerte" (AGA 21/20.417).

Al día siguiente, "fue la policía a buscarme a la casa" por lo que optó por refugiarse en el Consulado de la República de Panamá, donde permaneció desde el 26 de enero de 1938 al 27 de enero de 1939 (AGA 21/20.417; Camón Aznar 1984: 33; Pallol 2014: 653654), cuando entraron las tropas del general Franco en Barcelona.

El 30 de enero se presentó ante Javier Lasso de la Vega, el 19 de febrero y el 2 de marzo realizó en Barcelona declaraciones para su depuración, y el 5 de abril de 1939 presentó en Vitoria una instancia solicitando la revisión de su sanción, que fue tramitada con relativa prontitud. Fue aceptada por el Juez Instructor el 1 de mayo, emitiéndose la Orden de 27 de mayo de 1939 (BOE del 12 de junio), sustituyéndose su "separación definitiva del servicio y baja en el escalafón" por una "traslación forzosa a otra universidad sin poder solicitar nuevo traslado durante cinco años e inhabilitación definitiva para cargos directivos", siendo destinado a su ciudad natal, la Universidad de Zaragoza (AGA 21/20.417). El decreto venía firmado por Alfonso García-Valdecasas, Delegado de Educación Nacional de Falange y vinculado con Hedilla hasta 1937 (Thomàs 2014: 40-41, 60), posteriormente Subsecretario del primer Ministerio de Educación Nacional desde 1938, “con máxima generosidad me ofreció la cátedra en las Universidades que había vacantes: Barcelona y Zaragoza", no optando por Barcelona en la que había impartido durante la República, incorporándose a Zaragoza, su ciudad natal, a inicio del curso 1939-40, en la cual su maestro Domingo Miral escogió la docencia de griego y le cedió el curso de Arte (Camón Aznar 1984: 36-37). Alfonso García-Valdecasas había sido catedrático de Derecho Civil en la Universidad de Salamanca entre 1927 y 1931, cuando sacó la cátedra de la Universidad de Granada, de donde era originario. En 1931 estaba vinculado a la Agrupación al Servicio de la República, uno de los tres partidos de la Alianza Republicana a la que pertenecía también el Partido Radical de Camón Aznar. Miembro fundador de Falange y candidato del partido en 1933 por Granada, Alfonso García-Valdecasas fue uno de los testigos de confianza de Camon Aznar en su declaración de 2 de marzo de 1939 (AGA 21/20.417). Al cesar el general Franco a Sainz Rodríguez como Ministro de Educación Nacional, el 27 de abril de 1939, hasta la formación del segundo gobierno del general Franco, el 9 de agosto, el ministerio fue detentado de forma interina por el carlista Tomás Domínguez Arévalo, Conde de Rodezno, Ministro de Justicia, quien delegó todas las actuaciones del ministerio en el Subsecretario, Alfonso García-Valdecasas (Alted Vigil 1991: 103).

Otro apoyo importante fue el zaragozano Carlos Sánchez del Río Peguero (Camón Aznar 1984: 36), que había sido Secretario General de la Universidad de Zaragoza desde 1935, y se había incorporado a los servicios centrales del Ministerio de Educación Nacional del Gobierno de Burgos en 1938.

El tribunal de la oposición se decidió por el Ministerio el 29 de enero de 1942 (BOE del 4 de febrero), presidido por José Ferrandis Torres, Consejero Nacional de Educación y catedrático de Epigrafía y Numismática de la Universidad de Madrid. Era íntimo amigo de Camón Aznar y lo había puesto como uno de sus tres principales avaladores en su declaración para su depuración (AGA 21/20.417). Como secretario, el también aragonés Martín Almagro Basch, catedrático de Historia Antigua Universal y de España de la Universidad de Santiago de Compostela, agregado a la Universidad de Barcelona; y entre los vocales, Antonio García y Be1lido, catedrático de Arqueología de la Universidad de Madrid; y Diego Angulo Iñíguez, catedrático de Historia del Arte de Doctorado, posteriormente convertida en Historia del Arte Moderno y Contemporáneo de la Universidad de Madrid; con ambos Camón Aznar había tenido estrechos contactos en Madrid en 1937, hasta su marcha a Barcelona (AGA 21/20.417). A ambos el levantamiento les sorprendió en zona republicana, en el caso de Angulo de vacaciones en la playa de Comarruga (Tarragona), hasta tener que abandonar Madrid hacia Valencia en octubre de 1937 con la evacuación ordenada por el gobierno republicano y desplazarse poco después a Barcelona (Mateo 2002: 28-31). Finalmente, como tercer vocal, el falangista Francisco Alcayde Vilar (1939), catedrático de Lógica Fundamental de la Universidad de Valencia, Decano de la Facultad de Letras y autor de El concepto de Nación según José Antonio (AGA 31/1505).

En teoría Camón Aznar no podía presentarse a la oposición, al no poder solicitar otro puesto hasta 1944, "La sanción que me impusieron me impedía acceder a esa universidad" de Madrid (Camón Aznar 1984: 37). Sin embargo, el Ministerio de Educación Nacional decidió admitirle como firmante en la lista provisional del 5 de febrero de 1942 (BOE del 10 de febrero), y se le mantuvo en la lista definitiva del 25 de marzo (BOE del 4 de abril) (AGA 31/1505). 
No solo fue eso, sino que jubilado el catedrático de la Universidad de Zaragoza, Domingo Miral López, por Orden Ministerial del 19 de febrero de 1942, ese mismo día del 25 de marzo se informaba por parte del Ministerio a la Universidad de Zaragoza que Camón Aznar se encargaba ya como titular -y recuperaba plaza de catedrático- de la cátedra de Historia del Arte de la Universidad de Zaragoza (AGA 31/1505).

Resulta obvio que Camón Aznar estaba recibiendo fuertes apoyos desde dentro del Ministerio de Educación Nacional. Aparte de Alfonso García-Valdecasas, algunos de ellos tuvieron que llegar a través de Rafael Sánchez Mazas, miembro de la Junta Directiva de Falange desde su fundación en 1933, nombrado por Franco como Ministro sin cartera, a la vez que Ibáñez Martín en Educación Nacional, entre el 9 de agosto de 1939 y el 15 de agosto de 1940 . No sólo figuraba con Camón Aznar en el mismo procedimiento judicial en Barcelona durante 1938, cuando a ambos los condenaron a muerte, sino que Camón Aznar lo pone como uno de sus testigos de sus declaraciones en su depuración (AGA 21/20.417). Lo lógico es que todas las influencias confluyesen en el pamplonés Jesús Rubio GarcíaMina, Secretario General de Falange desde junio 1939, futuro Ministro de Educación desde el 16 de febrero de 1956, que entró con Ibáñez Martín como nuevo Subsecretario del Ministerio de Educación Nacional el 6 de octubre de 1939, sustituyendo a García-Valdecasas. Otra opción sería a través del ingeniero gaditano José Pemartín San Juan, primero Jefe del Servicio de Enseñanza Superior y Media con Sáinz Rodríguez desde el 5 de febrero de 1938 y luego Director General de Enseñanza Superior y Media con Ibáñez Martín, encargado de nombrar a los tribunales de las oposiciones, monárquico como García-Valdecasas.

No obstante, para resolver definitivamente su situación, probablemente aconsejado desde el Ministerio, Camón Aznar escribió por último personalmente al Ministro, Ibáñez Martín, el 23 de marzo, indicando su "esforzada adhesión a los ideales de la España Nacional" y "un trabajo que quiere estar dedicado íntegramente y sin reservas a la exaltación de los ideales nacionales", colaborando "en las revistas más representativas de los actuales ideales nacionales. Así en Escorial, Santo y Seña, Misión" (AGA 21/20.417; Pallol 2014: 655).

Además, Camón Aznar (1940) había reforzado su catolicismo que plasmó en su publicación de Dios en San Pablo, "escrito todo en la Embajada" de Panamá en 1938 (Camón Aznar 1984: 34). Según nos indica, "Sólo la religiosidad podía compensar un pesimismo trascendental que me hubiera llevado a la desesperación. Creo que esos arrebatos de espiritualidad religiosa fueron entonces muy frecuentes" (Camón Aznar 1984: 32). Este catolicismo trascendental era muy bien acogido por Ibáñez Martín, a quien Falange calificaba como "colaborador incondicional y fiel instrumento de la obra", por su estrecha vinculación al Opus Dei (Rodríguez Jiménez 2000: 421-422).

La decisión final fue tomada personalmente por el propio ministro quien, en nota manuscrita de 27 de marzo de 1942, en la carta de Camón Aznar, consideró "accédase a lo solicitado por estimarse se halla fundada en importantes y poderosas razones de equidad y justicia", decidiendo el levantamiento de la sanción, siendo emitida Orden Ministerial el 30 de marzo, confirmándolo en su nueva cátedra de Zaragoza "sin imposición de sanción". No obstante, para evitar alguna reclamación se especificó en nota manuscrita del mismo día 30 que "por orden del Sr. Ministro que no se publique" en el BOE. Solo fue comunicado por el subsecretario del Ministerio al Director General de Enseñanza Universitaria y al Rector de la Universidad de Zaragoza (AGA 21/20.417; Pallol 2014: 655).

Un aspecto llamativo es que Martínez Santa-Olalla optó por no presentarse a la plaza cuando se convocó a los candidatos el 27 de abril. Tres personas no le eran favorables, Ferrandis, con quien nunca tuvo una relación estrecha; Almagro Basch, de quien se había distanciado mucho a raíz de que firmó el concurso de traslado a la cátedra de Historia Primitiva del Hombre, convocada el 28 de abril de 1941 (Mederos 2010-11: 378-380), el cual se declaró desierto por el Consejo Nacional de Educación en mayo de 1942 (Sánchez Gómez 2001: 265 n. 18; Gracia 2009: 131), una vez ya convocado el concurso de esta plaza; y García y Bellido, por el distanciamiento de Martínez Santa-Olalla con Obermaier para tratar de ocupar su cátedra. En cambio, García y Bellido trataba de convertirse en su principal heredero en la Real Academia de la Historia. Los tres habían participado en una reunión con Obermaier en junio de 1939 (FD2005/1/17 p. 60, 22-6-1939; Gracia 2009: 104; Mederos 2010-11: 375).

El destino de la escuela de Gómez-Moreno y su cátedra de Arqueología Arábiga también quedaba dependiente de la decisión de dos personas de la escuela de Obermaier -García y Bellido, Almagro Basch- y otra vinculada a ella a pesar de ser discípulo de GómezMoreno -Ferrandis-. Previamente, Obermaier había decidido la promoción de García y Bellido a la cátedra de Arqueología en diciembre de 1931, en detrimento de Carriazo, discípulo de Gómez-Moreno (Mederos 2010: 66-67). 
La única persona que podría ser más próxima a Camps era Diego Angulo, secretario del Instituto Diego de Velázquez del CSIC, en el que figuraba como colaborador Camps, que había heredado la cátedra de Tormo (BOE del 11 de diciembre de 1940) y era un importante discípulo de Gómez-Moreno, pero por su estricta formación en Historia del Arte era más próximo a los puntos de vista de Camón Aznar. Por otra parte también conocía desde hacía años a Camón, y ambos como discípulos de Gómez-Moreno, en el curso de doctorado de 1922-23, habían viajado con él y Elías Tormo a una visita a Mallorca (Gómez-Moreno Rodríguez 1995: 315).

En la oposición, desde el primer examen, quedó evidente que el candidato era Camón Aznar, catedrático desde 1927 y con 43 años en el momento de la oposición. En el primer examen se indica que presenta el "Sr. Camón una formación más amplia en el campo de la Historia del Arte y en el Sr. Camps una labor divulgadora digna de la mayor estima". En la segunda prueba se señala, "el Sr. Camón presenta una amplísima memoria de más de 1.600 páginas y además un libro titulado 'El arte desde su esencia' [Camón Aznar, 1940], puede considerarse este trabajo excepcional en unas oposiciones (...) su calificación tiene que ser magnífica (...) el Sr. Camps (...) su memoria (...) cumplen con el reglamento" (AGA 31/1505). El libro lo acabó de redactar durante el año que permaneció en la embajada de Panamá en Barcelona en 1938 y "Parte se había publicado en una revista de la Universidad de Barcelona (Camón Aznar 1984: 34), y hasta 1939 había pensado titularlo El arte en la Fenomenología (AGA 21/20.417).

En el tercer examen, "El Sr. Camón explicó de manera magistral su lección sobre 'la miniatura mozárabe, especialmente los beatos (...) el Sr. Camps disertó sobre la arquitectura Normanda de Sicilia, su lección bien documentada". Las diferencias empezaron a marcarse aún más en los últimos exámenes, así en la quinta prueba, según el tribunal, "el Sr. Camón clasificó y comentó con una extraordinaria brillantez los diez monumentos artísticos que le entregaron reproducidos fotográficamente (...) su[s] clasificación[es] fueron de plena maestría (...) el Sr. Camps clasificó con acierto y maestría seis de los monumentos citados, en los otros cuatro sus opiniones no fueron tan exactas". En el sexto examen, "El Sr. Camón desarrolló los dos temas de un modo admirable; en ambos puso de relieve su dominio de la Historia del Arte Medieval (...) fue un trabajo acabado y perfecto. El Sr. Camps estudió con acierto los temas, aunque el de Arquitectura Gótica Inglesa estuvo falto de datos concretos y el de Arquitectura Almohade no se trataron los monumentos españoles con la debida extensión". El resumen final del tribunal señalaba el 19 de mayo que "existe una evidente superioridad en el Sr. Camón cuya labor de Profesor es de diez y seis años de docencia universitaria mientras el Sr. Camps no lleva más que siete años de Ayudante de cátedra, además la visión general de la Historia del Arte en el Sr. Camón es más amplia y revela una formación completísima en la Filosofía del Arte y Estética y su erudición es extraordinaria (...) el Sr. Camps Cazorla ha revelado una seria formación científica y ha realizado unos ejercicios muy brillantes", votando los cinco miembros del tribunal a Camón Aznar, que fue nombrado nuevo catedrático el 26 de mayo de 1942 (BOE del 12 de junio) (AGA 31/1505).

Es aún más claro Camón Aznar (1984: 38), "La oposición a la cátedra de Arte Medieval de la Universidad de Madrid la vencí fácilmente. Mi preparación era intensa. Sólo el trabajo de Metodología tenía cinco volúmenes. Uno de bibliografía. Y en otro hacía la historia del arte medieval por generaciones" si bien "fueron algo humillantes para mí (...) uno de los pocos sometidos a esta prueba después de quince años de catedrático de Universidad". La cátedra supuso su incorporación automática al Patronato del Museo Arqueológico Nacional, que efectuó el 8 de octubre de 1942 (AMAN Libro Actas Patronato $\mathrm{n}^{\circ} 84$, p. 63r).

Quizás el mejor ejemplo de las conexiones que tenía Camón Aznar (1984: 38-39) en el Ministerio de Educación fue que ingresando en 1942 en la sección de Arte del CSIC, al año siguiente ya dispuso de una revista propia, la Revista de Ideas Estéticas, con 4 fascículos trimestrales, un privilegio que sólo gozaba el secretario del Instituto Diego de Velázquez de Arte y Arqueología, Diego Angulo, con el Archivo Español de Arte, y Antonio García y Bellido, con el Archivo Espanol de Arqueología.

Un resultado de la desaparición de la cátedra de Arqueología Arábiga y de la potenciación de los perfiles de Historia del Arte por el Marqués de Lozoya como Director General de Bellas Artes fue que Camps, que había estado vinculado a las excavaciones de Sanchorreja de la Edad del Hierro y Castiltierra de época visigoda hasta 1935, orientó cada vez más su investigación hacia la Historia del Arte, y sus artículos utilizaron como cauce científico el Archivo Español de Arte (Camps 1941b, 1942, 1943a y 1943b), no el Archivo Español de Arqueología. 


\section{LA EXCAVACIÓN DE MEDINA AZAHARA}

Después de la Guerra Civil, en la primera propuesta de presupuesto para 1939-40, destinado a excavaciones en Medina Azahara, Madinat al-Zahrā', "la ciudad brillante", fundada por Abd al-Rahman III, el primer califa omeya de Córdoba en el siglo X d.C., solo figuran el arquitecto Félix Hernández Jiménez y el catedrático de veterinaria Rafael Castejón, con una partida mínima de 2.000 pesetas. En cambio, Camps y Navascués figuran en un intento de reanudar las excavaciones en Castiltierra con 8.000 pesetas (Gracia 2009: 267).

Para el año 1941, hay un sustancioso incremento de financiación para Medina Azahara, hasta 15.000 pesetas, y siguió a nombre de Hernández y Castejón. Por otra parte, Martínez Santa-Olalla arrebató a Camps y Navascués el yacimiento de Castiltierra por "su importancia, interés político y conveniencia e imprimirles un ritmo acelerado", asignándose 10.000 pesetas. A cambio, les ofreció a ambos reanudar la excavación de Sanchorreja con otras 10.000 pesetas (Gracia 2009: 268-269). Cuando ese mismo año hubo que presentar un presupuesto reducido, desaparecieron las partidas para los tres yacimientos, pero Martínez Santa-Olalla contaba con financiación paralela de Falange para excavar en Castiltierra (Gracia 2009: 270). En todo caso, no se libró dinero en 1940 y 1941.

En la partida de 1942 continuó la propuesta de excavación de Sanchorreja con 10.000 pesetas por Camps y Navascués, y siguieron desaparecidas Castiltierra y Medina Azahara (Gracia 2009: 274). En cambio, se ha sugerido que fueron concedidas 10.000 pesetas para Medina Azahara en 1942 a nombre de Enrique Salinas según Díaz-Andreu (2011: 49), lo que extraña porque no figuran ni Hernández ni Castejón. En la memoria de 1943 de Castejón (1945: 12, 41, 61, 1959-60: 146, 160161) no se hace ninguna mención de campaña en 1942 , pues solo se reanudarían al año siguiente. La excavación de Sanchorreja tampoco llegó a efectuarse. Primero se redujo la subvención de 10.000 a 8.000 pesetas el 20 de julio de 1942. Después, Navascués dimitió el 18 de septiembre alegando sus múltiples ocupaciones como Inspector General de Museos. Finalmente, solo 4 días después, el 22 de septiembre, lo hizo Camps alegando que era una dirección conjunta y que ya en esa época del año no podría efectuarse la excavación por el frío (Gracia 2009: 276, 278).

Un cambio significativo fue que Camps fue comisionado en diciembre de 1942 por la Dirección General de Bellas Artes para depositar en el Museo Arqueológico Nacional fondos cerámicos de Medina Azahara y Málaga que completasen sus colecciones (AGA 31/4643), de lo cual se derivaron algunas publicaciones (Camps 1947a, 1947b; Castejón 1945: 62-64).

Asumida Castiltierra por Martínez Santa-Olalla, y paralizada la excavación de Sanchorreja, a partir de 1943 reaparece de nuevo la financiación para la excavación de Medina Azahara, y por primera vez el permiso figura a nombre de Camps, junto con Castejón y Hernández, siendo el yacimiento mejor financiado con 50.000 pesetas; el siguiente fue Mérida, asignado a Serra Ràfols, con 40.000 pesetas y los restantes yacimientos no pasaban de 10.000 pesetas (Gracia 2009: 280). Aunque en la memoria de 1943, Castejón (1945: 61) habla en plural sobre los directores, por alguna razón la firma en solitario.

Por decisión personal del Marqués de Lozoya, Director General de Bellas Artes, Camps fue nombrado Comisario Local de Excavaciones de Medina Azahara, pues quería que Gómez-Moreno o alguien que le representara figurase en estas excavaciones. Lo nombró pese a la actitud contraria del Comisario General, Martínez Santa-Olalla, quien argumentaba que al residir en Madrid, Camps exigiría dietas y que había sido "inoperante" su trabajo cuando lo incluyó inicialmente con Hernández y Castejón (Gracia 2009: 247-248). No obstante, se ha sugerido por Díaz-Andreu (2011: 42), que quien fue nombrado inicialmente Comisario Local de Medina Azahara fue José de Calasanz Serra Ràfols el 24 de junio de 1942, aunque lo lógico es que ese nombramiento fuese para Mérida.

Para 1944 se asignaron 35.000 pesetas para Medina Azahara, pero ahora en el permiso figuraba primero el arquitecto Hernández, Castejón y por último Camps. El yacimiento siguió siendo el mejor financiado, pero hay partidas de 20.000 pesetas consignadas a Serra Ràfols en Mérida, Martínez Santa-Olalla y Mergelina (Gracia 2009: 282-283)

No sabemos por qué Camps no figura en el permiso de 1945, consignado solo a Castejón, ahora como primer firmante, y Hernández, donde la partida volvió a descender hasta 20.000 pesetas, al mismo nivel que Serra Ràfols en Mérida y Cabré en Recópolis (Gracia 2009: 288). No obstante, hubo otras 135.000 pesetas adicionales del Servicio de Reconstrucciones Artísticas (Castejón 1959-60: 161). Se nos ha indicado por Fernando Valdés (com. pers.) que Camps no participaba en los trabajos de campo, sino que los llevaba en exclusiva el arquitecto Félix Hernández, lo que, de confirmarse, permitiría suponer que quizás Camps solo fuera responsable del estudio de la cerámica recuperada en la excavación. 
En cualquier caso, Camps reaparece como tercer codirector, junto con Castejón y Hernández en las partidas de 1946, con 20.000 pesetas, siendo de nuevo Medina Azahara el yacimiento mejor financiado, aunque Martínez Santa-Olalla dispone de 30.000 pesetas repartidas en tres partidas distintas, dentro de un descenso generalizado de la financiación (Gracia 2009: 370). También continuó en 1947 , con la partida reducida a 13.500 pesetas, mientras es ya superado por las excavaciones del Barón de Esponellà y Serra Ràfols en Barcelona con 20.000 pesetas, Martínez Santa-Olalla con 19.000 pesetas en dos partidas diferentes y Serra Ràfols en Mérida con 15.000 pesetas (Gracia 2009: 377-378). A partir de 1948 ya no hay partida económica para Medina Azahara, ni figura Camps vinculado a ningún yacimiento, pero la situación se superó porque en 1949 la Fundación Lázaro Galdiano concedió 477.425 pesetas para excavaciones y la restauración del salón de Abd al-Rahman III descubierto en 1944 (Castejón 1959-60: 161).

\section{VICEDIRECTOR DEL MUSEO ARQUEOLÓGICO NACIONAL Y CATEDRÁTICO DE HISTORIA DEL ARTE EN LA UNIVERSIDAD DE OVIEDO}

El Director General de Archivos y Bibliotecas, Miguel Bordonau Mas, que había sido nombrado por Ibáñez Martín para el cargo el 8 de mayo de 1947, decidió nombrar a Camps como Vicedirector del Museo Arqueológico Nacional el 15 de enero de 1948, aunque se había situado su nombramiento en 1949 (Pasamar y Peiró 2002: 155), lo que también implicaba casi duplicar su gratificación anual como Secretario pasando de 3.750 a 6.000 pesetas, puesto en el que tomó posesión el 12 de febrero (AMAN EP ECC 66 y 68; AGA $31 / 4643)$. La gratificación fue aumentada a 8.000 pesetas el 1 de marzo de 1949 (AGA 31/4643).

La pérdida de la cátedra de Arte Medieval, en mayo de 1942, frente a Camón Aznar, no significó su desvinculación de la Universidad de Madrid. En el curso 1942-43, se le nombró Profesor Auxiliar Temporal de Historia Universal el 9 de noviembre de 1942, con sueldo de 4.000 pesetas. En este puesto continuó durante el curso 1943-44, desde el 9 de noviembre de 1943 , con un aumento de sueldo a 5.000 pesetas, cesando el 30 de septiembre de 1944 . Fue renovado el 20 de febrero de 1945 con sueldo de 6.000 pesetas y finalmente nombrado Profesor Adjunto de Historia del Arte por 4 años, prorrogables por otros 4 años, el 9 de agosto de 1947 (Orden Ministerial del 24 de julio), tomando posesión el 7 de octubre, para impartir las asignaturas de Historia del Arte Medieval (Musulmán), Historia General del Arte, Historia del Arte en las Edades Moderna y Contemporánea e Historia del Arte HispanoAmericano (AGUCM EP GH 104/09-06/1; AGUCM P-462/68).

Una nueva oportunidad a acceder a una cátedra se abrió al convocarse el 27 de julio de 1946 (BOE del 7 de agosto) las cátedras de Historia del Arte de Oviedo y Santiago de Compostela, al ser Asturias una de los ámbitos predilectos de estudio de Camps, teniendo cuando falleció un libro en redacción para el CSIC sobre $E l$ arte del reino Astur-Leonés (AGA 31/4643; Camps 1948). El tribunal se nombró el 17 de octubre de 1946 (BOE del 18 de noviembre) y la lista definitiva de aspirantes se publicó el 10 de mayo de 1947 (BOE del 18 de junio). Sin embargo, la convocatoria se retrasó por la muerte del presidente del Tribunal, José Ferrandis Torres, catedrático de Epigrafía y Numismática de la Universidad de Madrid, el 19 de agosto de 1948 ( $A B C$ 21-8-1948: 8). Eso dio pie a una nuevo plazo de 2 meses para inscribirse nuevos aspirantes, abierto el 28 de septiembre de 1948 (BOE del 31 de octubre), que finalizó el 31 de diciembre, publicándose una segunda lista definitiva de aspirantes el 28 de febrero de 1949 (BOE del 10 de marzo). Por esta razón, pasó de vocal a presidente Francisco Javier Sánchez Cantón, de la escuela de Gómez-Moreno, el 4 de enero de 1949 y ascendió el segundo vocal suplente, Xavier de Salas Bosch, un discípulo de Elías Tormo, director de la tesis de Camps al jubilarse Gómez-Moreno. Por otra parte, otro miembro de la escuela de Gómez-Moreno, Antonio Gallego Burín, pidió al ministerio su renuncia, como hacía habitualmente, que fue aceptada el 5 de abril de 1949, siendo nombrado Ángel de Apraiz Buesa, catedrático de la Universidad de Valladolid (AGA 31/4016).

Sin embargo, al constituirse el tribunal el 28 de abril de 1949, no se presentaron los otros tres miembros del tribunal, el propio Apraiz, Francisco Murillo Herrera, catedrático de la Universidad de Sevilla, y Diego Angulo Íñiguez, miembro de la escuela de Gómez-Moreno, por encontrarse enfermo. En cambio, solo se presentaron dos de los suplentes, Julio Martínez SantaOlalla, nuevo segundo suplente, que se había resistido a nombrar a Camps como Comisario Local de Medina Azahara y había saqueado el despacho de Gómez-Moreno en el Centro de Estudios Históricos cuando entró en Madrid con las tropas del General Franco en 1939 (com. pers. M. Casamar a F. Valdés), y Camón Aznar, primer vocal suplente que había ganado la cátedra en 1941 frente a Camps. No lo hicieron otros suplentes por 
su lejanía, como Rafael Laínez Alcalá, jiennense y muy amigo de Camps, porque era catedrático en la Universidad de La Laguna, ni Fernando Jiménez-Placer Suárez, catedrático de la Universidad de Salamanca. Ese mismo día, informado por Sánchez Cantón, se nombró por el Ministerio como quinto vocal al Marqués de Lozoya, Juan de Contreras y López de Ayala (BOE del 3 de mayo), que había exigido el nombramiento de Camps para Medina Azahara, quien no estuvo presente en la presentación, pero fue comunicado a los candidatos, quienes firmaron su aceptación (AGA 31/4016).

Los candidatos presentados fueron Manuel Chamoso Lamas, de 37 años, nacido en Cano (Cuba) y residente en Madrid, colaborador del Marqués de Lozoya y a partir de 1951 responsable de excavaciones en Orense, que la firmó desde el 2 de octubre de 1946. Valentín de Sambricio López, de Palma de Mallorca, con 42 años, funcionario del CFABA, que lo hizo el 20 de septiembre de 1949. El zaragozano Francisco Abbad Ríos, Profesor Auxiliar en la Universidad de Madrid, con 35 años, el 30 de septiembre. El valenciano Felipe María Garín Ortiz de Taranco, catedrático de la Escuela Superior de Bellas Artes de Valencia, con 38 años, el 11 de noviembre. El más tardío en completar su documentación, hasta el 24 de enero de 1950, fue el candidato de más edad, 50 años, y profesor en su ciudad de nacimiento, Valencia, Vicente Ferrán y Salvador (AGA 31/4016). Además, firmaron José María Azcárate y Ristori, discípulo de Gómez-Moreno y Diego Angulo, con 40 años, y Emilio Camps, que sacaron las plazas y cuyas solicitudes se debieron separar para el expediente personal de catedráticos.

Dos de los firmantes no se presentaron el 28 de abril de 1949, pero eran los más jóvenes. El sevillano José Guerrero Lovillo, con 29 años, alumno de Diego Angulo, que la firmó el 8 de diciembre de 1948; y Juan José Martín González, con 25 años, que había nacido en Alcazarquivir, en el protectorado de Marruecos, y residía en Valladolid, donde fue alumno de Cayetano de Mergelina, que la firmó el 24 de diciembre. Ese mismo día la había firmado otro candidato que no fue admitido, el sevillano José Hernández Díaz, con 42 años, catedrático de la Escuela Superior de Bellas Artes de Santa Isabel de Hungría en Sevilla (AGA 31/4016).

La oposición tuvo cierta polémica por los cambios que habían ocurrido en la composición del tribunal, que debilitaron a algunos opositores como Vicente Ferrán, al haber muerto Ferrandis, su director de tesis doctoral. Al ser Ferrán también abogado, presentó diferentes escritos por no cumplirse aspectos de la reglamentación. Primero el 1 de junio, al haberse acabado el $4^{\circ}$ ejercicio, porque Chamoso no había acabado su tema y a Azcárate ya se le había convocado al $5^{\circ}$ ejercicio sin haberlo presentado, escrito que apoyó Abbad, vistas ya las preferencias del tribunal. Lo volvió a hacer el 3 de junio, al sortearse los temas del $6^{\circ}$ ejercicio, por estar solo presentes el presidente y el secretario del tribunal y se reafirmó en otro finalizada la oposición el 5 de julio (AGA 31/4016; Pallol 2014: 661-662).

Como trabajo de investigación inédito a la cátedra, Camps presentó su Módulo, proporciones y composición de la arquitectura califal cordobesa, que se publicó póstumamente (Camps 1953; Gómez-Moreno Martínez 1953: 7).

A la plaza se presentaba ya como Profesor Adjunto de Historia del Arte, una notable docencia en la Universidad de Madrid que resumía hasta el curso 1950-51 en 1 curso de Arqueología Arábiga, 2 cursos de Historia del Arte Cristiano Medieval, 6 cursos de Historia del Arte Medieval y 7 cursos impartidos de Historia General del Arte, además de superar las 400 conferencias impartidas (AGA 31/4643) y tenía el mejor perfil para estas cátedras de los candidatos presentados.

En la valoración final del tribunal de 3 de junio se indica que "aporta, junto a trabajos y resúmenes de valor didáctico sobre el arte prerrománico, el califal y el románico, su extensa tesis sobre el arte visigodo incorporada en la Historia de España dirigida por Menéndez Pidal y diversos catálogos de exposiciones y de instalaciones de museos. Además de una Historia del Arte Español todavía inédita, obras todas ellas seriamente construidas y de mérito didáctico. Su memoria trata del 'Módulo, proporciones y composición en la arquitectura califal', llena de novedades y gráficos cuidados" (AGA 31/4016).

Al final, Camps obtuvo 4 votos para la cátedra de Oviedo, con el único voto negativo de Martínez SantaOlalla, que lo hizo a favor de Manuel Chamoso, el segundo que había tenido una valoración más positiva, quien "presentó un número considerable de monografías, en especial sobre arquitectura (...) en Galicia" (AGA 31/4016). La razón fue que el tribunal había decidido apoyar como segundo candidato al gallego José María Azcárate, quien obtuvo al menos 3 votos para poder ir a Santiago, los de Sánchez Cantón, Salas Bosch y también Martínez Santa-Olalla, a sabiendas que era también el ámbito de estudio de Chamoso, pues Martínez Santa-Olalla tenía una relación muy estrecha con Sánchez Cantón y Angulo, mientras Camón Aznar optó por su paisano Abbad Ríos y el Marqués de Lozoya se inclinó por su antigua universidad de Valencia y votó a Felipe Garín (AGA 31/4016; Pallol 2014: 662), votos 
pactados muchas veces para quedar bien con los opositores y a la vez darles posibilidades para las siguientes oposiciones. Francisco Abbad, otro alumno de GómezMoreno con tesis en 1935 sobre El Románico en Cinco Villas, obtuvo el 24 de diciembre de 1952, al morir Camps, la cátedra de Oviedo y en 1958 pasó a la Universidad de Zaragoza.

Camps fue propuesto al Ministerio el 6 de septiembre de 1949 y nombrado como catedrático de Historia del Arte de la Universidad de Oviedo según Orden Ministerial del 7 de septiembre (BOE del 22 de septiembre) (AGA 31/4016). Tomó posesión por delegación el 5 de octubre, con efectos del 1 de octubre, en la propia Universidad de Madrid, para lo cual fue autorizado por el Ministerio el 12 de septiembre (AGUCM P-462/68), pues pidió excedencia de la cátedra y continuó en el Museo Arqueológico Nacional. No obstante, impartió conferencias en los cursos de verano de la Universidad de Oviedo, como en el de 1949, las cuales tenían gran calidad, como recuerda el filólogo granadino y académico de la lengua Gregorio Salvador Caja ( $A B C$ 209-2006: 68), "Hablaba Emilio Camps Cazorla sobre 'Modulo, construcción y forma de la arquitectura califal cordobesa'. Pues me deslumbró. Y me pregunté cómo se puede convertir un tema tan árido en cosa espléndida”. Esta buena aceptación por los alumnos también la resalta Gil Farrés (1952b: 129), que indica que "Sus alumnos amaron a Camps como a un ídolo", con "método amenísimo y muy personal".

Es llamativo, en cambio, su contraste con Camón Aznar (1984: 38), "Debo de declarar que yo no he tenido nunca un gran entusiasmo pedagógico. Creo en la letra impresa más que en la hablada (...) Y en las clases he procurado restringir toda retórica, hacerlas secas y eruditas (...) Se me ha achacado alguna vez que no tengo discípulos".

La cátedra reforzó aún más el perfil hacia la Historia del Arte de Camps (1950, 1951a), quien comenzó a participar en congresos de esa especialidad. Primero en España, como el celebrado en Córdoba en 1947 de la Asociación Española para el Progreso de las Ciencias donde presentó "Las llamadas 'soluciones de fortuna' en la arquitectura islámica de España". Continuó con su invitación a asistir, como representante del CSIC, a la Reunión Internacional de Historiadores del Arte del Primer Milenio en el Instituto de Arte de la Universidad de Maguncia, para lo cual solicitó permiso el 5 de mayo de 1950, siendo autorizado el día 8, y viajando del 30 de mayo al 5 de junio, donde presentó "San Salvador de Valdedios y el arte asturiano de los siglos IX y X”. Finalmente, también fue invitado en 1951 a la $3^{\mathrm{a}}$
Reunión para el Estudio de la Alta Edad Media, celebrada en Suiza, donde presentó una comunicación sobre "San Miguel de Liño" o Lillo en Asturias (AGA 31/4643). Quizás para participar en este congreso y realizar alguna visita adicional, Camps solicitó "ausentarse al extranjero para ampliar estudios de Arte y Arqueología”, estancia autorizada por Navascués el 27 de julio de 1951 (AMAN EP ECC 71).

Al crearse la Fundación Lázaro Galdiano, el 18 de julio de 1948, fue encargado de catalogar la colección de arte de 8.700 piezas legada y aceptada por el estado (BOE del 27 de diciembre de 1947) del editor navarro, José Lázaro Galdiano, fallecido el 1 de diciembre de 1947, a propuesta del Director General de Bellas Artes, el Marqués de Lozoya, en febrero de 1948 (AGA 31/4643). La colección quedó expuesta en su residencia familiar, el palacete de Parque Florido en la calle Serrano 122, la cual fue abierta al público el 27 de enero de 1951 (Camps 1951b). Desde julio de 1950, Camps fue subdirector de la Fundación. Precisamente allí volvió a coincidir con Camón Aznar que fue elegido por el Patronato como director de la fundación, junto con la archivera María Brey y como bibliotecario Antonio Rodríguez-Moñino. Un museo que para Camón Aznar (1984: 52, 54) era "mi hogar, mi solaz y mi trabajo (...) Paso las mañanas en mi despacho de la Fundación".

Precisamente, Camps no se incorporó a la cátedra, quedando "sin poder desempeñarla, ocupado en el inventario de la magna colección artística que constituye el Museo Lázaro Galdiano" (Gómez-Moreno Martínez 1953: 9). La catalogación de las 8.700 piezas le ocupó entre marzo de 1948 y mayo de 1950, realizando ficha, fotografía y ubicación topográfica (AGA 31/4643; Camps 1952). En todo caso, la cátedra ya no era una prioridad para Camps, quien comentó a Gil Farrés (1952a: 26) que "se había presentado únicamente (...) para satisfacción de un vivo [Gómez-Moreno] y de un muerto [Taracena]".

\section{ELECCIÓN COMO DIRECTOR DEL MUSEO ARQUEOLÓGICO NACIONAL Y FALLECIMIENTO}

Después de las vacaciones de verano de 1951, tras producirse el cambio ministerial con la entrada como nuevo Ministro de Educación de Joaquín Ruiz Giménez el 18 de julio en su octavo equipo ministerial, "Navascués se creyó obligado a dimitir su dirección interina por considerarse un cargo de confianza personal 
del Ministro saliente", por lo que se convocó un concurso para ocupar la plaza de director (AMAN Libro Actas Patronato 85 p. 116r).

La plaza de director salió el 8 de octubre de 1951, "a concurso entre funcionarios en servicio activo del Cuerpo Facultativo de Archiveros, Bibliotecarios y Arqueólogos" y Camps presentó su solicitud para acceder a la dirección del Museo Arqueológico Nacional el 10 de diciembre de 1951 (AMAN EP ECC 72). $\mathrm{Su}$ instancia fue tratada en el Patronato del MAN el 8 de enero de 1952, que remitió al museo el 12 de enero informe del Presidente del Patronato, Manuel Escrivá de Romaní, Conde de Casal, para el Director General de Archivos y Bibliotecas, y también para el secretario del Patronato y Museo, Vázquez de Parga, quien envió al Ministerio oficio "informando favorablemente la instancia presentada por el Sr. Camps solicitando la dirección del museo, con el ruego de que la firme para remitirla a la mayor brevedad" (AMAN EP ECC 73-74). Por su parte, el Conde de Casal señalaba al Ministerio también el día 12 el "informe favorable acerca de la aptitud y condiciones de Don Emilio Camps Cazorla para ocupar la subsodicha dirección" (AGA 31/4643).

Sin embargo, falleció súbitamente el 28 de enero de 1952 (AMAN EP ECC 75), de un colapso mientras se afeitaba por la mañana (Carriazo 1972/2001: 175), lo que acabó suponiendo la continuidad y elección de Navascués como director del museo el 17 de mayo de 1952 (AMAN EP JMNJ 35). Se ha sugerido que fue el mismo día que apareció publicado su nombramiento (Carriazo 1972/2001: 175; Pasamar y Peiró 2002: 155; Caballero Zoreda 2010: 12 n. 38) o se comentaba que fue mientras se vestía para la toma de posesión ( $T$. Camps a V. Salve, com. pers.), aunque los contemporáneos indicaban que murió "poco antes de que se anunciara la resolución del concurso a la dirección" (Laínez 1953: 96), y más en concreto, "su nombramiento oficial estaba ya firmado para dicho cargo, pero aún no hecho público" (Gil Farres 1952b: 130).

El caso es que se emitió "Orden de 15 de enero de 1952 nombrando Director del Museo Arqueológico Nacional al funcionario del Cuerpo Facultativo de Archiveros, Bibliotecarios y Arqueólogos, D. Emilio Camps Cazorla (...) Insértese en el B.O. del Estado". La Orden Ministerial de Joaquín Ruiz-Giménez indicaba que "El Excmo. Sr. Ministro dice (...) teniendo en cuenta que el Sr. Camps, único concursante, reúne las condiciones y méritos necesarios para ocupar dicha plaza, ha tenido a bien nombrar a D. Emilio Camps Cazorla, funcionario del Cuerpo Facultativo de Archiveros, Bibliotecarios y
Arqueólogos, Director del Museo Arqueológico Nacional con todas las atribuciones y prerrogativas inherentes a dicho cargo", orden que fue remitida al Director interino, Navascués, y al interesado, el propio Camps. No salió publicado en el B.O.E. y "no se tramitó por haber fallecido el Sr. Camps el mismo día en [que] se le daba salida", según se indica en una nota manuscrita (AGA 31/4643). El funeral se celebró en los Padres Benedictinos de Montserrat de la calle de San Bernardo el 8 de febrero.

\section{CONCLUSIONES}

Por el temprano fallecimiento de su padre y el traslado con su madre y hermana a vivir junto a su tío en Madrid, Emilio Camps empezó a trabajar desde los 13 años, en 1916, como dibujante en la sección de Arqueología del Centro de Estudios Históricos y en el Instituto Católico de Artes e Industrias de Madrid, a la vez que cursaba el bachillerato que finalizó en 1920. Dos años después comenzó los estudios en Filosofía y Letras, especialidad de Historia, entre 1922-25. Ya comenzó desde 1927 a publicar en temas de arquitectura visigoda, asturiana, califal, mozárabe y mudéjar.

A partir del curso 1929-30, con 26 años, Camps se convirtió en el Profesor Ayudante de la cátedra de doctorado de Arqueología Arábiga. Al año siguiente, con Gómez-Moreno primero como vocal y después como presidente del tribunal de oposiciones al Cuerpo Facultativo de Archiveros, Bibliotecarios y Arqueólogos, alcanzó el $4^{\circ}$ puesto entre las 27 plazas, que le permitió ingresar como Asistente en prácticas en julio de 1930 en el Museo Arqueológico Nacional. Para ampliar su formación científica, Gómez-Moreno, aprovechando su cargo de Director General de Bellas Artes, nombró a Camps, Navascués y Taracena como representantes españoles para la Conferencia Internacional de Museos de la Sociedad de las Naciones, otorgándoles una bolsa de viaje para visitar Italia y Francia durante 3 meses entre octubre y diciembre de 1930. Por otra parte, dentro del museo, se fue especializando en cerámica hispanomusulmana, organizando la apertura de nuevas salas que el estallido de la guerra paralizó.

$\mathrm{Su}$ formación inicial de campo fue realizada bajo la supervisión de Cabré y Mergelina, con excavaciones de megalitos del Neolítico Final y Calcolítico en Montefrío (Granada) (1925), necrópolis ibéricas en Tugia (Jaén) (1927), poblados ibéricos en Azaila (Teruel) (1930) o de la Segunda Edad del Hierro en Las Cogotas (Ávila) (1928) y Santa Tecla (Pontevedra) (1928). 
A partir de 1930 su investigación siguió dos líneas principales, el ámbito visigodo con las excavaciones en la iglesia visigoda de San Pedro de la Nave (Zamora), continuada con excavaciones junto a Navascués en la necrópolis visigoda de Castiltierra (Segovia) en 1932, 1933 y 1934/35 y en el poblado del Bronce Final y Edad del Hierro del Castro de los Castillejos (Sanchorreja, Ávila), inicialmente con Cabré en 1931, y en 1932, 1933 y 1934/35 junto con Navascués.

La jubilación de Gómez-Moreno en febrero de 1935 le abrió la posibilidad de poder acceder a la nueva cátedra de Arqueología Medieval (Cristiana y Árabe), para lo cual defendió su tesis doctoral Arte hispano-visigodo: ensayo de síntesis, dirigida por Elías Tormo, en el mes de noviembre. Su principal competidor fue el catedrático José Camón Aznar, que impartía desde 1928 como acumulada la asignatura de Arqueología, Numismática y Epigrafía en la Universidad de Salamanca. Pese a contar con un tribunal favorable, al interrumpirse el concurso que se iba a celebrar a partir del 25 de junio de 1936 por la inestabilidad antes del estallido de la Guerra Civil, le imposibilitó acceder a la cátedra.

Justo al acabar la guerra, en abril de 1939, fue nombrado Secretario del Museo Arqueológico Nacional, unos días después de la elección de Taracena como Director, y ambos colaboraron en el desembalaje del museo y la reinstalación de las salas de cerámica hispano-musulmana. Se incorporó en 1940 como Colaborador en el Instituto Diego de Velázquez de Arte y Arqueología y desde el curso 1939-40 continuó como Profesor Encargado de Curso de Arqueología Arábiga en la Universidad de Madrid. La cátedra volvió a ser convocada en 1941, cambiando el Ministerio su perfil, de Arqueología Medieval por Arte Medieval, y mediante el nombramiento de un nuevo tribunal próximo a Camón Aznar, quien además de ser catedrático desde 1926, se le quería premiar desde el Ministerio por su colaboración con Falange como militante desde 1937 en Madrid y Barcelona, quien ganó la plaza en mayo de 1942.

Camps procedía de una familia modesta pues su padre había sido maestro en Jaén, y la relación inicial con Gómez-Moreno procedía de la amistad de su tío cuando eran jóvenes. Su trabajo en el Instituto Católico de Artes e Industrias de Madrid le vinculó en 1916, con 14 años, a los jesuitas y a una educación cristiana, trabajo que perdió al quemarse el instituto en incidentes poco después de la proclamación de la Segunda República en 1931. Su ascenso profesional fue claramente vinculado a Gómez-Moreno, que lo apoyó en el Cuerpo Facultativo y lo eligió como su ayudante en la Universidad de
Madrid. Su diario de 1930 nos lo muestra como un católico practicante que confesaba y comulgaba habitualmente. Su investigación no era solo el ámbito islámico, sino estaba muy focalizada en el periodo visigodo y el cristianismo primitivo, tanto a través del estudio de su arte para la tesis doctoral, como con sus excavaciones en la necrópolis de Castiltierra. Por ello, la cátedra de Arqueología Arábiga fue convertida en 1935 en Arqueología Medieval (Cristiana y Árabe). Por su ideología conservadora y no estar afiliado a ningún sindicato en Madrid, fue declarado "cesante" el 9 de septiembre de 1936 por "desafecto al régimen", perdió su casa próxima al frente y solo fue readmitido en febrero de 1937. Vuelto a cesar en octubre de 1937, al no marcharse de Madrid a Valencia, tuvo que vivir durante el final de la Guerra Civil como profesor particular de bachillerato, no sorprendiendo que el Juzgado Militar de Funcionarios lo considerase de "ideología derechista". La ausencia de militancia política falangista y sus modestos cargos en el Museo Arqueológico Nacional o en la Universidad de Madrid, poco podían competir con la red de relaciones de alto nivel que disponía Camón Aznar en el gobierno. Alfonso García-Valdecasas, primer Subsecretario de Educación Nacional y compañero suyo como catedrático en Salamanca; Serrano Suñer, Ministro del Interior y antiguo diputado por Zaragoza donde Camón tenía gran peso social; o Rafael Sánchez Mazas, Ministro sin cartera, condenado con él a muerte en Barcelona en 1938.

A partir de finales de 1942, Camps estuvo encargado del estudio de la cerámica depositada en el Museo Arqueológico Nacional de las excavaciones en Medina Azahara y entre 1943-47, fue con el arquitecto Félix Hernández y el catedrático de veterinaria Rafael Castejón el codirector de las campañas de excavación, cuyo peso era llevado por Hernández.

Emilio Camps continuó vinculado a la Universidad de Madrid, como Profesor Auxiliar Temporal desde el curso 1942-43 y desde 1947 como Profesor Adjunto de Historia del Arte. La convocatoria de una cátedra de Historia del Arte en la Universidad de Oviedo en 1946, cuyo concurso no se realizó hasta 1949, le permitió obtener finalmente la cátedra, pero pidió excedencia porque había sido nombrado en enero de 1948 como nuevo Vicedirector del Museo Arqueológico Nacional y desde el mes de marzo como responsable de la catalogación de la colección Lázaro Galdiano.

La cátedra reforzó su perfil hacia la Historia del Arte dentro de la Arqueología, con una narrativa muy descriptiva y positivista que se adapta bien a sus principales temas de trabajo, la arquitectura y la cerámica, 
que plasmó en sus catálogos sobre colecciones cerámicas del Museo Arqueológico Nacional o del museo Lázaro Galdiano, y solo es algo más interpretativo en su análisis sobre la geometría de la arquitectura islámica en su pequeño libro póstumo, Módulo, proporciones y composición en la arquitectura califal cordobesa.

Tras la dimisión de Navascués en 1951 por el cambio ministerial y la entrada de Ruiz-Giménez, fue propuesto como nuevo director por el Patronato del museo y nombrado por Orden Ministerial de 15 de enero, pero su muerte inesperada, el 28 de enero de 1952, con sólo 48 años, impidió que tomara posesión del cargo.

Las cartas de condolencia muestran el gran aprecio personal que se tenía por su persona, lo que contrasta con las misivas más formales y en menor número recibidas en el Museo Arqueológico Nacional cuando el fallecimiento de Taracena, aunque solo su diario de viaje de 1930 nos permite aproximarnos algo a su personalidad. También sus alumnos hablan bien de sus capacidades docentes y el cuidado en la documentación gráfica arqueológica de sus excavaciones nos lo muestra como una persona muy detallista, en comparación con su compañero de excavaciones, Navascués, quien, por otra parte, fue el principal beneficiario indirecto de su fallecimiento, pues le permitió continuar como director del Museo Arqueológico Nacional.

\section{Agradecimientos}

Queremos agradecer las atenciones de Daniel Gozalbo en el Archivo General de la Administración (AGA), de Aurora Ladero en el Archivo del Museo Arqueológico Nacional (AMAN), de Ana Rocasolano y Susana Donoso en el Archivo General de la Universidad Complutense de Madrid (AGUCM), de Alberto González con el Fondo Documental Pérez de Barradas (FD2005) en el Museo de San Isidro de Madrid, de Javier Moya Morales en el Instituto Gómez Moreno (IGM) de la Fundación Rodríguez-Acosta en Granada, los datos familiares proporcionados por Teresa Camps y las sugerencias de Virginia Page y Fernando Valdés. Dos fotos proceden del Legado Cabré en el CeDAP de la UAM, por gentileza de Juan Blánquez, y otras dos del archivo fotográfico del Museo Arqueológico Nacional gracias a la atenta gestión de V. Page. Se adscribe al Grupo de Investigación Hum F-003 de la Universidad Autónoma de Madrid, sobre estudios historiográficos, dirigido por J. Blánquez.

\section{BIBLIOGRAFÍA}

Alcayde Vilar, F. (1939): El concepto de Nación según José Antonio. Discurso leído en la solemne apertura del curso académico de 1939 a 1940. Valencia, Anales de la Universidad de Valencia 16, 1939-40. Imprenta Hijo de F. Vives Mora.

Alted Vigil, A. (1991): "Bases político-ideológicas y jurídicas de la universidad franquista durante los ministerios de Sainz Rodríguez y primera época de Ibáñez Martín (1938-1945)", en J.J. Carreras y M.A. Ruiz Carnicer (eds.), La Universidad española bajo el régimen de Franco (1939-1975) (Zaragoza, 1989): 95-124. Zaragoza, Institución Fernando el Católico.

Álvarez-Ossorio y Farfán de los Godos, F. de P. (1936): "Las reformas del Museo Arqueológico Nacional", en E. Camps, Cerámica española: catálogo sumario del Museo Arqueológico Nacional (Nuevas instalaciones: 6-11. Madrid, Museo Arqueológico Nacional-Imprenta de Blass.

Arias, I. y Balmaseda, L.J. (2016): La necrópolis de época visigoda de Castiltierra (Segovia). Excavaciones dirigidas por E. Camps y J.M. ${ }^{a}$ de Navascués, 1932-1935. Materiales conservados en el Museo Arqueológico Nacional. I. Presentación de sepulturas y ajuares. Madrid, Museo Arqueológico Nacional-Ministerio de Educación, Cultura y Deportes.

Beltrán Lloris, M. (1995): Azaila. Nuevas aportaciones deducidas de la documentación inédita de Juan Cabré Aguiló. Zaragoza, Institución Fernando el Católico.

Beltrán Lloris, M. (2012-13): “Juan Cabre y Azaila. Documentación inédita”. Caesaraugusta 83: 13222.

Caballero Zoreda, L. (e.p.): "Vida y trabajo de Manuel Gómez-Moreno. Con la arquitectura altomedieval como tema". Centenario del Centro de Estudios Históricos (Madrid 2010). Madrid, Consejo Superior de Investigaciones Científicas.

Cabré Aguiló, J. (1925): “Arquitectura hispánica. El sepulcro de Toya”. Archivo Español de Arte y Arqueología 1 (1): 73-101.

Cabré Aguiló, J. (1932): Excavaciones en Las Cogotas. Cardeñosa (Ávila). La Necrópolis. Memoria de la Junta Superior de Excavaciones Arqueológicas 120. Madrid, Tipografía de la Revista de Archivos, Bibliotecas y Museos.

Camón Aznar, J. (1940): Dios en San Pablo. Zaragoza, Librería General. 
Camón Aznar, J. (1954): Las artes y los pueblos de la España Primitiva. Madrid, Espasa-Calpe.

Camón Aznar, J. (1984): Perfil autobiográfico. Zaragoza, Museo e Institución Camón Aznar.

Camps Cazorla, E. (1927): "Puertas mudéjares con inscripción eucarística". Archivo Español de Arte y Arqueología 3 (8): 197-220.

Camps Cazorla, E. (1929a): Arquitectura cristiana primitiva, visigoda y asturiana. Cartillas de Arquitectura Española 3. Madrid, Imprenta de A. Marzo.

Camps Cazorla, E. (1929b): "Una obra inédita del siglo XVI: el retablo de la Iglesia Parroquial de Santa Cruz, en Cardeñosa (Ávila)". Archivo Español de Arte y Arqueología 5 (14): 145-156.

Camps Cazorla, E. (1930): Arquitectura califal y mozárabe. Cartillas de Arquitectura Española 4. Madrid, Imprenta de A. Marzo.

Camps Cazorla, E. (1930/2015): Diario de Viaje. V. Salve y S. Espinós (eds.). Fondos Documentales del Museo Arqueológico Nacional. Madrid, Ministerio de Educación, Cultura y Deportes.

Camps Cazorla, E. (1931/1933): “Armario morisco, procedente de Toledo, nota descriptiva". Museo Arqueológico Nacional. Adquisiciones en 1930: 7 pág. 2 lám. Madrid, Imprenta de Blass.

Camps Cazorla, E. (1932): "Descripción de la laude de Sahagún", en Laude o Cubierta de mármol del sepulcro de Alfonso Ansúrez, hijo del Conde Pedro Ansúrez, entregada a España por el Fogg Art Museum de la Universidad de Harvard, Cambridge, Massachusetts (EE.UU). Madrid, Patronato del Museo Arqueológico Nacional. Imprenta de Blass.

Camps Cazorla, E. (1932/1933a): "Sillas del coro de Santa Clara de Astudillo (Palencia)". Museo Arqueológico Nacional. Adquisiciones en 1931: 8 pág. 2 lám. Madrid, Imprenta de Blass.

Camps Cazorla, E. (1933b): "Los marfiles de San Millán de la Cogolla". Museo Arqueológico Nacional. Adquisiciones en 1931: 16 pág. 10 lám. Madrid, Imprenta de Blass.

Camps Cazorla, E. (1934): "Tejidos visigodos de la Necrópolis de Castiltierra (Segovia)". Homenaje a Mélida. Anuario del Cuerpo Facultativo de Archiveros, Bibliotecarios y Arqueólogos 2: 87-96.

Camps Cazorla, E. (1935): El arte románico en España. Colección Pro Ecclesia et Patria-Junta de Acción Católica. Barcelona, Labor.

Camps Cazorla, E. (1936): Cerámica española: catálogo sumario del Museo Arqueológico Nacional (Nuevas instalaciones). Madrid, Museo Arqueológico Nacional-Imprenta de Blass.
Camps Cazorla, E. (1936): "El arte español en tiempos de los Reyes Católicos", en L. Pericot (dir.): Historia de España. Gran Historia General de los pueblos hispánicos. IV. La Casa de Austria (siglos XVI y XVII) Barcelona, Instituto Gallach.

Camps Cazorla, E. (1939-40): “El visigotismo de Quintanilla de las Viñas". Boletín del Seminario de Estudios de Arte y Arqueología 6: 125-134.

Camps Cazorla, E. (1940a): "El arte hispanovisigodo", en R. Menéndez Pidal (coord.), Historia de España. Tomo III. España Visigoda: 433-608. Madrid, Espasa Calpe.

Camps Cazorla, E. (1940b): "Sala cuarta Edad Media. Sala quinta Edad Moderna". Museo Arqueológico Nacional. Guía de las instalaciones de 1940. Resumen de Arqueología Española: 35-71. Madrid, Hauser y Menet.

Camps Cazorla, E. (1940-41): "El visigotismo de San Pedro de la Nave". Boletín del Seminario de Estudios de Arte y Arqueología 7: 73-80.

Camps Cazorla, E. (1941a): Hierros antiguos españoles. Madrid, Escuela y Artes Oficios Artísticos de Madrid.

Camps Cazorla, E. (1941b): "La Custodia de la Catedral de Sigüenza y su autor". Archivo Español de Arte 14 (47): 461-472.

Camps Cazorla, E. (1941c): "Orfebrería". Exposición de orfebrería y ropas de culto (Arte español de los siglos XV al XIX). Madrid, Comisaría General del Servicio de Defensa del Patrimonio Artístico Nacional.

Camps Cazorla, E. (1941d): "Una visita a la Exposición de orfebrería y ropas de culto". Boletín de la Sociedad Española de Excursiones 45: 206-213.

Camps Cazorla, E. (1942): "El relicario tortosí de San Eulalio". Archivo Español de Arte 15 (49): 27-34.

Camps Cazorla, E. (1943a): "Las fechas en la platería madrileña de los siglos XVIII y XIX". Archivo Español de Arte 16 (56): 88-96.

Camps Cazorla, E. (1943b): "Un ciervo califal de bronce". Archivo Español de Arte 16 (58): 212-222.

Camps Cazorla, E. (1943c): La cerámica medieval española. Madrid, Escuela y Artes Oficios Artísticos de Madrid.

Camps Cazorla, E. (1943-44): "Rarezas iconográficas de San Francisco de Betanzos". Boletín de la Comisión de Monumentos de Orense 14: 86-94.

Camps Cazorla, E. (1947a): "Cerámica y vidrios de Medina Zahara (Córdoba)". Adquisiciones del Museo Arqueológico Nacional 1940-45: 148-154. Madrid, Museo Arqueológico Nacional. 
Camps Cazorla, E. (1947b): “Cerámica musulmana de Málaga”. Adquisiciones del Museo Arqueológico Nacional 1940-45: 154-161. Madrid, Museo Arqueológico Nacional.

Camps Cazorla, E. (1948): "Revisión de algunos problemas de los monumentos ramirenses". Boletín del Instituto de Estudios Asturianos 2 (5): 95-126.

Camps Cazorla, E. (1950): "Moorish Art: SpanishMoslem Art". The Art in Spain. The Studio magazine 1950: 4 p. London, The Studio.

Camps Cazorla, E. (1951a): "Lo morisco en el arte de los Reyes Católicos". Revista de Archivos, Bibliotecas y Museos 57: 623-636.

Camps Cazorla, E. (1951b): "El mejor museo privado del mundo". Mundo Hispánico 39: 13-18.

Camps Cazorla, E. (1952): “Un lote de piezas célticas en el Museo Lázaro Galdiano", en A. Beltrán (ed.), II Congreso Nacional de Arqueología (Madrid, 1951): 355-362. Cartagena, Secretaría General de los Congresos Arqueológicos Nacionales.

Camps Cazorla, E. (1953): Módulo, proporciones y composición en la arquitectura califal cordobesa. Madrid, Consejo Superior de Investigaciones Científicas.

Camps, E. y Terán, M. (1928): “La obra maestra de los broncistas españoles: la reja del sepulcro de Cisneros". Archivo Español de Arte y Arqueología 5 (13): 107-108.

Camps, E. y Navascués, J.Ma . de (1931): "El ara de los marfiles de San Millán de la Cogolla". Archivo Español de Arte y Arqueología 7 (20): 167-170.

Carriazo y Arroquia, J. de M. (1972): “Con Don Manuel Gómez-Moreno en el Centro de Estudios Históricos", en Homenaje al Profesor Carriazo. II: xlilxi. Sevilla, Universidad de Sevilla.

Carriazo y Arroquia, J. de M. (1972/2001): “Con Don Manuel Gómez-Moreno en el Centro de Estudios Históricos", en J.L. Carriazo Rubio (ed.), Juan de Mata Carriazo y Arroquia. Perfiles de un centenario (1899-1999): 173-182. Sevilla, Universidad de Sevilla.

Carriazo y Arroquia, J. de M. (1977): El maestro Gómez-Moreno contado por el mismo. Discurso leído el día 8 de Mayo de 1977, en su recepción pública, por el Excmo. Sr. D. Juan de Mata Carriazo y Arroquia y contestación del Excmo. Sr. D. Emilio García Gómez. Sevilla, Real Academia de la Historia.

Carro, X.; Camps, E. y Fernández Oxea, X.R. (1933): "Arqueoloxía relixiosa de Melide". Terra de Melide: 251-302. Santiago de Compostela, Editorial Nós.

Castejón y Martínez de Arizala, R. (1945): Excavaciones del Plan Nacional en Medina Azahara
(Córdoba). Campaña de 1943. Informes y Memorias 8. Madrid, Ministerio de Educación Nacional.

Castejón y Martínez de Arizala, R. (1959-60): “Los monumentos árabes de Córdoba. La gran Mezquita Aljama. Medina al Zahra". Al-Mulk, Anuario de Estudios Arabistas 1: 139-162.

Díaz-Andreu García, M. (2011): "La Historia de la Prehistoria andaluza durante el periodo franquista (1939-1975)", en Memorial Luis Siret (Antequera, Málaga, 2010): 39-72. Sevilla, Junta de Andalucía.

Gil Farrés, O. (1952a): “D. Emilio Camps Cazorla". Boletín de la Dirección General de Archivos y Bibliotecas 2: 25-26.

Gil Farrés, O. (1952b): "Necrologías. Emilio Camps Cazorla". Revista de Archivos, Bibliotecas y Museos $4^{\text {a }}$ S. 1: 129-131.

Gómez-Moreno Martínez, M. (1934): “La destrucción de la Cámara Santa de Oviedo". Diario de Madrid, 11 de noviembre de 1934.

Gómez-Moreno Martínez, M. (1953): “Prólogo", en E. Camps, Módulo, proporciones y composición en la arquitectura califal cordobesa: 7-10. Madrid, Instituto Diego de Velázquez, Consejo Superior de Investigaciones Científicas.

Gómez-Moreno Martínez, M. (1951-58/1977): "Un currículum vitae, autógrafo, del maestro Gómez-Moreno", en J. de M. Carriazo, El maestro Gómez-Moreno contado por el mismo. Discurso leído el día 8 de Mayo de 1977, en su recepción pública, por el Excmo. Sr. D. Juan de Mata Carriazo y Arroquia y contestación del Excmo. Sr. D. Emilio García Gómez: 53-62. Sevilla, Real Academia de la Historia.

Gómez-Moreno Rodríguez, Mª.E. (1995): Manuel Gómez-Moreno Martínez. Madrid, Centro de Estudios Ramón Areces.

Gracia Alonso, F. (2009): La arqueología durante el primer franquismo (1939-1956). Barcelona, Bellaterra Arqueología.

Gracia, F. y Fullola, J.M . (2006): El sueño de una generación. El crucero universitario por el Mediterráneo de 1933. Barcelona, Universitat de Barcelona.

Laínez Alcalá, R. (1953): “Emilio Camps Cazorla”. Zephyrus 3 (1): 95-96.

Maluquer de Motes y Nicolau, J. (1957): "Un interesante lote de bronces, hallado en el Castro de Sanchorreja (Ávila)". Zephyrus 8: 241-256.

Maluquer de Motes y Nicolau, J. (1958): El Castro de los Castillejos en Sanchorreja. Estudio de las excavaciones realizadas por D. Juan Cabré, D. Joaquín María de Navascués y D. Emilio Camps, de 1931 a 
1935. Ávila-Salamanca, Diputación de Ávila-Universidad de Salamanca.

Martínez Santa-Olalla, J. (1931): "Sobre algunos hallazgos de bronces visigóticos en España”. JpekJahrbuch für Prähistorische und Ethnografische Kunst 7: 57-60.

Martínez Santa-Olalla, J. (1933): Excavaciones en la necrópolis visigoda de Herrera de Pisuerga (Palencia). Memorias de la Junta Superior de Excavaciones y Antigüedades 1932 (4), 125. Madrid, Tipografía de la Revista de Archivos, Bibliotecas y Museos.

Mateo Gómez, I. (ed.) (2002): Diego Angulo Íñiguez, historiador del Arte. Madrid, Biblioteca de Historia del Arte. Consejo Superior de Investigaciones Científicas.

Mederos Martín, A. (2010) "Una trayectoria rota. Juan de Mata Carriazo, Catedrático de Prehistoria e Historia de España Antigua y Media de la Universidad de Sevilla". Spal 19: 61-96. http://dx.doi. org/10.12795/spal.2010.i19.03

Mederos Martín, A. (2011-12): "Martín Almagro Basch, formación y consolidación como catedrático de Prehistoria (1911-1943)". Boletín del Seminario de Estudios de Arqueología 77-78: 335-416.

Mederos Martín, A. (2015): “Tiempos difíciles. Blas Taracena Aguirre, depuración y ascenso a director del Museo Arqueológico Nacional (1937-40)", en J. García Sánchez, I. Mañas y F. Salcedo (eds.), Navigare necesse est. Estudios en homenaje a José María Luzón Nogué: 320-332. Madrid, Universidad Complutense.

Mergelina y Luna, C. de (1941-42): “La estación arqueológica de Montefrío (Granada). I. Los dólmenes". Boletín del Seminario de Estudios de Arte y Arqueología 8 (28-30): 33-106.

Mergelina y Luna, C. de (1943-44): “Tugia. Reseña de unos trabajos". Boletín del Seminario de Estudios de Arte y Arqueología 10 (34-36): 13-32.
Mergelina y Luna, C. de (1944-45): "La Citania de Santa Tecla. La Guardia (Pontevedra)". Boletín del Seminario de Estudios de Arte y Arqueología 11 (37-39): 13-54.

Mergelina y Luna, C. de (1945-46): “La estación arqueológica de Montefrío (Granada). II. La acrópolis de Guirrete (Los Castillejos)". Boletín del Seminario de Estudios de Arte y Arqueología 12 (40-42): 15-26.

Montes Domínguez, E. (1957): "Pórtico", en R. Sánchez Mazas, Fundación, Hermandad y Destino. Madrid, Ediciones del Movimiento.

Pallol Trigueros, R. (2014): "La Historia, la Historia del Arte, la Paleografía y la Geografía en la universidad nacionalcatólica", en L.E. Otero Carvajal (ed.), La Universidad nacionalcatólica. La reacción antimoderna: 535-775. Madrid, Universidad Carlos III.

Pasamar, G. y Peiró, I. (2002): Diccionario Akal de Historiadores Españoles Contemporáneos (18401980). Madrid, Ediciones Akal.

Rodríguez Jiménez, J.L. (2000): Historia de Falange Española de las JONS. Madrid, Alianza Editorial.

Salve, V. y Espinós, S. (eds.) (2015): Emilio Camps Cazorla, Diario de Viaje. Madrid, Fondos Documentales del Museo Arqueológico Nacional. Ministerio de Educación, Cultura y Deportes.

Sánchez Gómez, L.A. (2001): “Etnología y Prehistoria en la Universidad Complutense de Madrid. Crónica de una desigual vinculación (1922-2000)". Complutum 12: 249-272.

Thomàs, J.M. (1992): Falange, Guerra Civil, Franquisme. F.E.T. de las J.O.N.S. de Barcelona en els primers anys de regime franquista. Biblioteca Abat Oliba 116. Barcelona, Publicacions de l'Abadia de Montserrat.

Thomàs, J.M. (2014): El gran golpe. El 'caso Hedilla' o cómo Franco se quedó con Falange. Barcelona, Debate. 